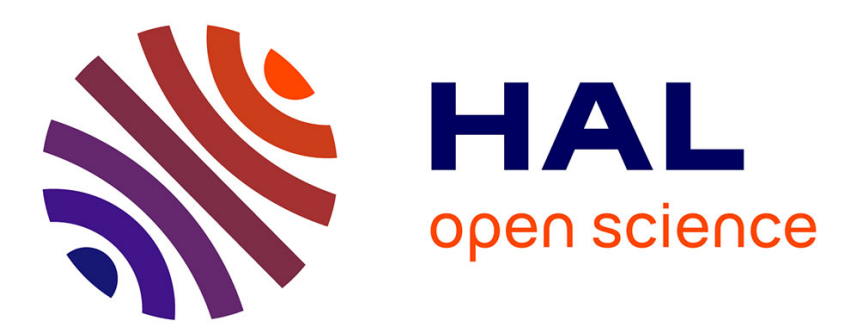

\title{
A general kinetic model for the photothermal oxidation of polypropylene
}

Alexandre François-Heude, Emmanuel Richaud, E Desnoux, Xavier Colin

\section{To cite this version:}

Alexandre François-Heude, Emmanuel Richaud, E Desnoux, Xavier Colin. A general kinetic model for the photothermal oxidation of polypropylene. Journal of Photochemistry and Photobiology A: Chemistry, 2015, 296, pp.48-65. 10.1016/j.jphotochem.2014.08.015 . hal-01086383

\section{HAL Id: hal-01086383 https://hal.science/hal-01086383}

Submitted on 24 Nov 2014

HAL is a multi-disciplinary open access archive for the deposit and dissemination of scientific research documents, whether they are published or not. The documents may come from teaching and research institutions in France or abroad, or from public or private research centers.
L'archive ouverte pluridisciplinaire HAL, est destinée au dépôt et à la diffusion de documents scientifiques de niveau recherche, publiés ou non, émanant des établissements d'enseignement et de recherche français ou étrangers, des laboratoires publics ou privés. 


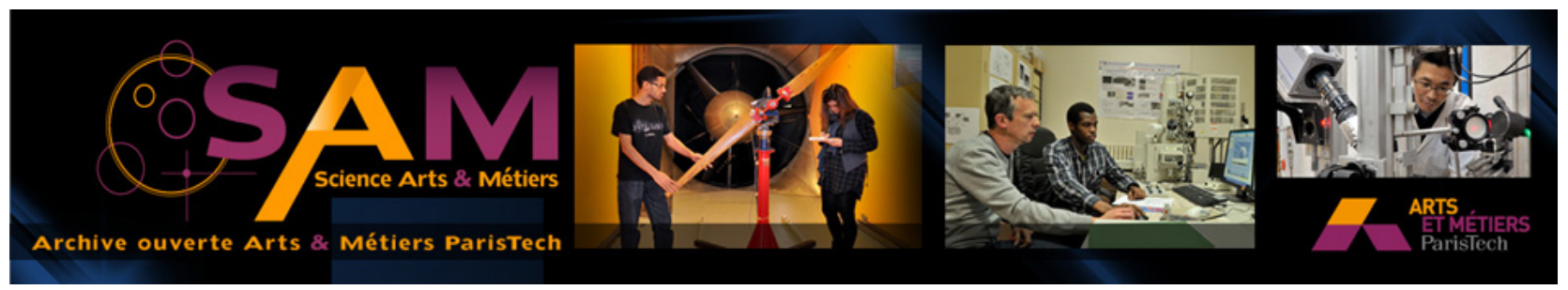

Science Arts \& Métiers (SAM)

is an open access repository that collects the work of Arts et Métiers ParisTech researchers and makes it freely available over the web where possible.

This is an author-deposited version published in: http://sam.ensam.eu

Handle ID: .http://hdl.handle.net/10985/8966

\section{To cite this version :}

Alexandre FRANCOIS-HEUDE, Emmanuel RICHAUD, E DESNOUX, Xavier COLIN - A general kinetic model for the photothermal oxidation of polypropylene - Journal of Photochemistry and Photobiology A: Chemistry - Vol. 296, p.48-65 - 2015 


\title{
A general kinetic model for the photothermal oxidation of polypropylene
}

\author{
A. François-Heude ${ }^{\text {a,b,* }}$, E. Richaud ${ }^{a}$, E. Desnoux ${ }^{b}$, X. Colin $^{\text {a }}$ \\ a Arts et Metiers ParisTech, PIMM Laboratory, CNRS UMR 8006, Paris, France \\ ${ }^{\mathrm{b}}$ Renault, Research Department, Guyancourt, France
}

\begin{abstract}
A B S T R A C T
A general kinetic model for the photothermal oxidation of polypropylene has been derived from the basic auto-oxidation mechanistic scheme in which the main sources of radicals are the thermolysis and photolysis of the most unstable species, i.e hydroperoxides. Thermolysis is a uni- or bi-molecular reaction whose rate constant obeys an Arrhenius law. In contrast, photolysis is exclusively a unimolecular reaction and its rate constant is independent of temperature. According to the quantum theory, this latter is proportional to the energy absorbed by photosensitive species and thus, accounts for the impact of UVlight intensity and wavelength on the global oxidation kinetics.

The validity of this model has been checked on iPP films homogeneously oxidized in air over a wide range of temperatures and UV-light sources. It gives access to the concentration changes of: (i) primary (hydroperoxides) and secondary (carbonyls) oxidation products, (ii) double bonds, (iii) chain scissions and crosslinking nodes, but also to the subsequent changes in molecular masses. These calculations are in full agreement with the photolysis results reported by Carlsson and Wiles in the 70s [1-3]. However, the model seems to be only valid for UV-light energies equivalent to about 10 suns as upper boundary, presumably because of multiphotonic excitations or chromophores photosensitization (i.e. termolecular photo-physical reactions), both enhanced at high irradiances.
\end{abstract}

\section{Introduction}

There is an increasing demand of automotive industry for the development of numerical calculation tools allowing to criticize and enhance the representativeness of accelerated aging testing methodologies and to predict the lifetime of polymer parts. In this perspective, non-empirical kinetic approaches appear to be most relevant since they would capitalize knowledge. The first attempts to model the oxidation kinetics of hydrocarbon polymeric substrates were done by Tobolsky et al. $[4,5]$ with the perspective of predicting their long-term behavior. Their analytical model was derived from an oversimplified mechanistic scheme in which the radical chain oxidation was composed of only four elementary chemical steps. Initiation consisted in the formation of radical species either from the thermal decomposition of hydroperoxides or from the effect of extrinsic factors (e.g. a radiation source).

* Corresponding author. Tel.: +33 1442464 13; fax: +33 144246382 .

E-mail address: Alexandre.FRANCOIS-HEUDE@ensam.eu (A. François-Heude).
Propagation took place in two successive stages: the rapid addition of oxygen onto alkyl radicals followed by the slower hydrogen abstraction on polymer substrate by peroxy radicals. Finally, termination consisted only in the bimolecular combination of peroxy radicals. Thus, according to these authors, thermal and photochemical oxidation could be described by a very close mechanistic scheme differing only by their initiation step. A mathematical expression for oxidation rate was obtained through the conventional concepts of chemical kinetics by making four simplifying assumptions: (1) unicity of reactive site, i.e. oxidation occurs exclusively on the most labile $\mathrm{CH}$ bond; (2) low conversion ratios of oxidation process, i.e. concentration of reactive sites remains virtually constant; (3) constancy of initiation rate in the case of oxidation induced by an extrinsic factor; (4) and steadystate for radicals concentrations in all oxidation cases, but also for hydroperoxides concentration in the case of pure thermal oxidation. This kinetic modeling approach turned out to be astonishingly efficient despite its apparent simplicity. It allowed predicting accurately the homogeneous thermo-, photo- and radio-oxidation of thin polymer films (typically $100 \mu \mathrm{m}$ thick) 
exposed under a sufficiently high oxygen partial pressure to fully saturate the sample in oxygen, i.e. to reach the so-called regime of oxygen excess.

Kinetic developments were then made by Bolland and Gee [6], Reich and Stivala [7,8], Cunliffe and Furneaux [9,10] and Audouin et al. [11], but also by Gillen et al. [12], with the objective to describe other oxidation regimes of lower oxygen concentration than oxygen excess. These authors added other possible termination reactions, namely bimolecular combinations of alkyl-alkyl and alkyl-peroxy radicals, to the previous mechanistic scheme. They obtained a hyperbolic expression for oxidation rate by making two additional simplifying assumptions (in addition to the previous four assumptions): (5) long kinetic chain; (6) and existence of an interrelationship between termination rate constants. This model allowed to describe the oxygen concentration dependence of the oxidation rate of thin polymer films and to determine the critical value of the oxygen partial pressure above which oxygen is in excess. Moreover, when coupled with the Fick's second law (for oxygen diffusion) into an oxygen balance equation, this model allowed also to accurately predict the concentration profiles of oxygen and oxidation products in thick polymer samples (typically few mm thick).

Since then, new kinetic developments were made by Gillen et al. [12] and Colin et al. [13,14] to reduce the number of questionable simplifying assumptions and thus, increase the robustness of the analytical kinetic model.

In the eighties, the advances of the previous decades in the elucidation of chain radical oxidation reactions and the emergence of new numerical algorithms especially adapted for solving stiff problems of chemical kinetics, enabled Sommersal and Guillet to envisage the development of a numerical model for polyolefins photooxidation [15]. Their approach consisted in considering all the possible elementary chemical steps (up to sixty) and assigning them a rate constant whose value was determined on model compounds, when possible. Such an exhaustive approach was very attractive since it enabled to eradicate all the questionable simplifying assumptions (except assumption 1), but it failed because the numerical problem to be solved was largely oversized. Indeed, for most oxidation cases, too many rate constants were unknown and some of them were experimentally out-of-reach.

This observation encouraged our research team to propose an alternative approach of kinetic modeling. It consists in deriving a kinetic model from a simplified, but realistic, oxidation mechanistic scheme by focusing on the critical oxidation path, i.e. constituted of the main contributory reactions to photothermal oxidation. In the case of pure thermal oxidation, it is called the "closed-loop mechanistic scheme" (CLMS) [16-18], since, the main source of radicals is the thermal decomposition of its main propagation products, i.e. hydroperoxides.

In the early 2000s, this numerical tool has been extended to solve oxidation problems initiated by extrinsic species or factors, in particular gamma-irradiation in a nuclear environment [19]. Now, it remains to extent this approach to the case of photothermal oxidation. However, the quantitative impact of UV-light on the initiation step of oxidation has not been clearly formalized. The introduction of a term of photo-induced initiation in a numerical model has been performed by Kiil in the case of the photooxidation of epoxy coatings, but the corresponding initiation rate has been described through an empirical law [20], whereas it would be possible to use the quantum theory. A criterion, based on the absorbed energy by photosensitive species, was recently proposed in this purpose and tested through an analytical model [21]. This theory allowed describing the competition between thermal and photochemical initiations during polypropylene oxidation. However, the analytical treatment prevented from introducing photochemical initiation by multiple photosensitive species, and the values of quantum yields were excessive compared with the experimental values reported by Carlsson and Wiles [1-3,22].

The objective of the present publication is to extend the numerical kinetic model, beforehand established for pure thermal oxidation, to the photothermal oxidation of isotactic polypropylene (iPP) by taking into account the additional effect of UV-light sources. After having checked its validity, this model will be used for investigating the relative predominance of two important photosensitive species (namely peroxide type species and ketones) in the initiation step of photothermal oxidation which, still today, remains a controversial topic in the literature.

\section{Experimental part}

\subsection{Materials}

The iPP under investigation was supplied as pellets by Aldrich (under the reference 427,888 ). Its main physico-chemical characteristics are: $\mathrm{MFI}\left[230^{\circ} \mathrm{C}, 216 \mathrm{~kg}\right]=12 \mathrm{~g} / 10 \mathrm{~min}, M_{\mathrm{w}}=250 \mathrm{~kg} \mathrm{~mol}^{-1}$, $M_{\mathrm{n}}=67 \mathrm{~kg} \mathrm{~mol}^{-1}$ and PI $=3.7$. Films of $80-135 \mu \mathrm{m}$ thick were processed by compression molding in a Gibitre laboratory press during $1 \mathrm{~min}$ at $200^{\circ} \mathrm{C}$ under $20 \mathrm{MPa}$, and then purified from their stabilizers by Soxhlet extraction for $48 \mathrm{~h}$ using dichloromethane as solvent prior to aging experiments.

\subsection{Photothermal aging}

In order to decouple UV-light from thermal effects, iPP films were exposed under different light intensities and temperatures, always in dry conditions. Photothermal aging experiments were mostly performed on films of $80 \mu \mathrm{m}$ thick in a series of SEPAP devices equipped with $80 \mathrm{~W}$ medium pressure arc mercury lamps having a borosilicate filter. To vary the light intensity, the number of lamps was changed from 2 to 4 lamps in a SEPAP 12-24 device, and from 6 to 8 lamps in a SEPAP 50-24 device. Both light intensity and emission spectrum were measured using a IL390C radiometer in the $295-415 \mathrm{~nm}$ range and a Avantes spectro-radiometer (AvaSpec $2048 \times 14-U S B 2,0.7 \mathrm{~nm}$ resolution) in the $250-750 \mathrm{~nm}$ range respectively. Temperature was fixed at 45,60 or $80^{\circ} \mathrm{C}$ according to the apparatus specifications and directly monitored on sample surfaces using a thermo-button temperature logger. A photothermal aging test was also performed on films of $135 \mu \mathrm{m}$ thick in a WeatherO'Meter device (WOM) equipped with a xenon lamp and borosilicate S/S filters. The black (BPT) and white standard (WST, i.e. chamber) temperatures were fixed at 70 and $55^{\circ} \mathrm{C}$ respectively. The temperature of the sample was found to be intermediary at $64^{\circ} \mathrm{C}$, whereas the irradiance at $340 \mathrm{~nm}$ was measured at $0.46 \mathrm{~W} \mathrm{~m}^{-2} \mathrm{~nm}^{-1}$, without water spraying. The thermal oxidation (in the absence of UV-light) was also investigated in air-ventilated ovens for temperatures ranging from 60 to $140^{\circ} \mathrm{C}$

To ensure the test reproducibility (between samples stemming from different batches during their purification from stabilizers) and to determine a sampling frequency suitable for an accurate description of the oxidation kinetics (particularly fast under the harsher aging conditions), it was decided to proceed in two stages:

- A non-destructive monitoring of carbonyl oxidation products by FTIR spectrophotometry, repeated for all aging conditions on samples coming from three different batches.

- Both destructive (hydroperoxide titration, gel permeation chromatography, DSC, etc.) and non-destructive analyses (FTIR spectrophotometry) on samples from different batches, periodically removed from the aging devices. 
This is the reason why different datasets are depicted for carbonyl products in most of the aging conditions.

\subsection{FTIR analyses}

FTIR analyses were performed using a PerkinElmer spectrophotometer ( 16 scans, $4 \mathrm{~cm}^{-1}$ resolution) in order to monitor aging by basing on the peak of carbonyl at $1713 \mathrm{~cm}^{-1}$ accounting for the stretching (or valence vibration) of the $\mathrm{C}=\mathrm{O}$ bond with a molar extinction coefficient fixed at $\varepsilon=300 \mathrm{~L} \mathrm{~mol}^{-1} \mathrm{~cm}^{-1}$. Actually, the FTIR absorbance only enables to perform semi-quantitative titration of the different carbonyl species due to overlapping of multiple carbonyl peaks (assigned to ketones, acids, esters, etc.).

The $\mathrm{C}=\mathrm{C}$ ethylenic unsaturations were also tentatively monitored using the peak at $1645 \mathrm{~cm}^{-1}$ which results from the stretching or valence vibration $v$ of vinyl, vinylidene and cisvinylene groups (peaks are assigned according to reference [23]). This mode of vibration appears at $1680 \mathrm{~cm}^{-1}$ for trans-vinylene and tri- or tetra-substituted olefins, and thus, is partially overlapped by the increasing carbonyl peaks of oxidation products. All the other characteristic peaks identified for vinyl (at 910 and $\left.990 \mathrm{~cm}^{-1}\right)$, vinylidene $\left(890 \mathrm{~cm}^{-1}\right)$, cis-vinylene $\left(690 \pm 40 \mathrm{~cm}^{-1}\right)$, trans-vinylene $\left(965 \mathrm{~cm}^{-1}\right)$ and tri-substituted olefins $(815 \pm 25$ $\mathrm{cm}^{-1}$ ) turns out to be unemployable either because of insufficient absorption or because of overlapping with polypropylene characteristic peaks. In such conditions, only the peak at $1645 \mathrm{~cm}^{-1}$ is relevant for monitoring the double bonds formed during the course of photothermal oxidation, in particular vinylidenes or trisubstituted olefins by disproportionation (see further termination steps 4 and 5), or cis- and trans- vinylene as well as vinyl groups by the Norrish 2 reaction. Although only a part of these species are titrated at $1645 \mathrm{~cm}^{-1}$, a value of $\varepsilon=20 \mathrm{~L} \mathrm{~mol}^{-1} \mathrm{~cm}^{-1}$ [24] was chosen for the molar extinction coefficient, after having checked that it successfully accounts for the concentration of $\mathrm{C}=\mathrm{C}$ double bonds, at least for those generated by disproportionation during thermal oxidation.

\subsection{Hydroperoxides titration}

The iodine method was chosen to perform hydroperoxides titration, instead of the sulfide dioxide or ferrous cyanate reactive methods, due to its better reliability for polypropylene $[25,26]$. This former is based on the reduction of hydroperoxides by sodium iodide in an acidic medium according to the reaction:

$\mathrm{R}_{3} \mathrm{COOH}+3 \mathrm{I}^{-}+2 \mathrm{H}^{-} \rightarrow \mathrm{R}_{3} \mathrm{COH}+\mathrm{I}_{3}^{-}+\mathrm{H}_{2} \mathrm{O}$

The concentration of $\mathrm{I}_{3}^{-}$ions was titrated by UV spectrophotometry at $355 \mathrm{~nm}$ using a PerkinElmer Lambda 35 device and a molar extinction coefficient of $\varepsilon=25000 \mathrm{~L} \mathrm{~mol}^{-1} \mathrm{~cm}^{-1}$. About $10 \mathrm{mg}$ of PP sample and $7 \mathrm{ml}$ of a solution of isopropanol and acetic acid solvents mixture (10:1) were introduced into a two neck glass flask equipped with a bulb condenser. When refluxing, $2 \mathrm{ml}$ of sodium iodide dissolved in isopropanol $\left(200 \mathrm{~g} \mathrm{~L}^{-1}\right)$ was added with a syringe throughout the side neck. After $10 \mathrm{~min}$, the mixture was quenched up to room temperature with $25 \mathrm{ml}$ of distilled water. It is noteworthy that the previous iodometry procedure does not enable discrimining between hydroperoxides, peracids and peresters. Dialkyl peroxides would not be titrated in theory except if chlorhydric acid is used instead of acetic acid as a catalyst. The accuracy on concentration measurement was estimated to be $\pm 7.5 \mathrm{~mol} \%$.

\subsection{Molecular weight measurement}

Gel permeation chromatography (GPC) experiments were performed with a PL-GPC 220 high temperature device
Table 1

Coefficients used for the universal calibration.

\begin{tabular}{llll}
\hline Materials & $\mathrm{K}\left(10^{3} \mathrm{ml} \mathrm{g}^{-1}\right)$ & $\alpha$ & References \\
\hline Polystyrene standards & 13.8 & 0.70 & {$[27,28]$} \\
Polypropylene & 15.2 & 0.76 & {$[29]$} \\
\hline
\end{tabular}

commercialized by Agilent Technologies. The GPC was equipped with a guard column and two columns branded PLGel Olexis as well as a refractive index detector. The eluent was 1,2,4trichlorobenzene (Chromasolv, Sigma-Aldrich) stabilized with 0.03 wt\% of 2,6-di-tert-butyl-4-methylphenol (BHT, Fluka). It was filtered with a $0.2 \mu \mathrm{m}$ pore size membrane (in PTFE, Whatman) before use. The injection volume was $200 \mu \mathrm{l}$ and the flow rate was $1.0 \mathrm{ml} / \mathrm{min}$. PP samples were dissolved in 1,2,4-trichlorobenzene/ BHT $(0.3 \mathrm{wt} \%)$ using a PL-SP 260-VS high temperature sample preparation system (PL Ltd.) at $135^{\circ} \mathrm{C}$ during $20 \mathrm{~min}$. The calibration curve was established from four Polystyrene Shodex narrow standards of respective molecular weights of 1,470,000, $257,000,46,500$ and $7,210 \mathrm{~g} \mathrm{~mol}^{-1}$. Results were then corrected using the so-called "universal calibration", based on the wellknown Mark-Houwink's relationship (Eq. (1)) with the coefficient values reported in Table 1.

$$
[\eta]=K \times M^{\alpha}
$$

\subsection{Crystallinity ratios measurement}

Differential scanning calorimetry (DSC) was performed on $10 \mathrm{mg}$ sample weight with a TA Q1000 calorimeter under a nitrogen flow. A temperature ramp of $10^{\circ} \mathrm{C} \mathrm{min}^{-1}$ from 30 to $200^{\circ} \mathrm{C}$ was applied in order to minimize the annealing phenomena. Crystallinity ratios were calculated taking a melting enthalpy for crystalline lamellae of $\Delta \mathrm{H}_{\mathrm{m}}^{0}=209 \mathrm{Jg}^{-1}$. The initial crystallinity value was $45 \pm 3$ wt $\%$.

\section{Theory}

\subsection{Multi-closed-loop mechanistic scheme (MCLMS)}

The basic idea of the kinetic modeling approach, first formulated by Tobolsky $[4,5]$, is that the different kinds of oxidative aging (i.e. thermo-, radio- and photo-oxidation) differ exclusively by the nature of their initiation step. Thus, the mechanistic scheme of photothermal oxidation can be obtained by introducing, into the now common "closed-loop mechanistic scheme" (CLMS) previously established for pure iPP thermal oxidation [30,31], additional initiation steps due to the effect of UV-light, in particular the photolysis of cleavable photosensitive species (i.e. chromophores). The CLMS has been recently updated for iPP $[30,31]$. It is briefly reminded in the next section.

\subsubsection{Thermal nucleus Initiation}

(1u) $\mathrm{POOH} \rightarrow 2 \mathrm{P}^{\bullet}+\left(1-\gamma_{1}\right) \mathrm{POH}+\gamma_{1} \mathrm{P}=\mathrm{O}+\mathrm{H}_{2} \mathrm{O}+\gamma_{\mathrm{s}} \mathrm{S}(-2 \mathrm{PH})\left(\mathrm{k}_{1 \mathrm{u}}\right)$

(1b) $2 \mathrm{POOH} \rightarrow \mathrm{P}^{\bullet}+\mathrm{PO}_{2}^{\bullet}+\left(1-\gamma_{1}\right) \mathrm{POH}+\gamma_{1} \mathrm{P}=\mathrm{O}+\mathrm{H}_{2} \mathrm{O}+\gamma_{\mathrm{S}} \mathrm{S} \quad(-\mathrm{PH})$ $\left(\mathrm{k}_{1 \mathrm{~b}}\right)$

$$
\begin{gathered}
\text { Propagation } \\
\mathrm{P}^{\bullet}+\mathrm{O}_{2} \rightarrow \mathrm{PO}_{2}^{\bullet}\left(\mathrm{k}_{2}\right)
\end{gathered}
$$

$\mathrm{PO}_{2}^{\bullet}+\mathrm{PH} \rightarrow \mathrm{POOH}+\mathrm{P}^{\bullet}\left(\mathrm{k}_{3}\right)$ 
Termination

$\mathrm{P}^{\bullet}+\mathrm{P}^{\bullet} \rightarrow \gamma_{4} \mathrm{P}-\mathrm{P}+\left(1-\gamma_{4}\right) \mathrm{PH}+\left(1-\gamma_{4}\right) \mathrm{F}+\gamma_{4} B\left(\mathrm{k}_{4}\right)$

$\mathrm{P}^{\bullet}+\mathrm{PO}_{2}^{\bullet} \rightarrow \gamma_{5} \mathrm{POOP}+\left(1-\gamma_{5}\right) \mathrm{POOH}+\left(1-\gamma_{5}\right) \mathrm{F}+\gamma_{5} B\left(\mathrm{k}_{5}\right)$

(6a) $\mathrm{PO}_{2}^{\bullet}+\mathrm{PO}_{2}^{\bullet} \rightarrow\left[\mathrm{PO}^{\bullet \bullet} \mathrm{OP}\right]_{\text {cage }}+\mathrm{O}_{2}\left(\mathrm{k}_{6 \mathrm{a}}\right)$

(6b) $[\mathrm{PO} \bullet \bullet \mathrm{OP}]_{\text {cage }} \rightarrow \mathrm{POOP}+B\left(\mathrm{k}_{6 \mathrm{~b}}\right)$

(6d) $[\mathrm{PO} \bullet \mathrm{OP}]_{\text {cage }} \rightarrow 2 \mathrm{P}^{\bullet}+2\left(1-\gamma_{1}\right) \mathrm{POH}+2 \gamma_{1} \mathrm{P}=\mathrm{O}+2 \gamma_{\mathrm{s}} \mathrm{S} \quad(-2 \mathrm{PH})$ $\left(\mathrm{k}_{6 \mathrm{~d}}\right)$

The CLMS constitutes the thermal nucleus of the mechanistic scheme for the photothermal oxidation of iPP. The main source of radicals is the thermal decomposition of hydroperoxides $(\mathrm{POOH})$ which are the primary oxidation products generated in the propagation step. Thereby, hydroperoxides govern the oxidation kinetics and determine the length of the induction period.

In this scheme, $\mathrm{PH}$ accounts for tertiary $\mathrm{CH}$ groups (i.e. methynes) which are considered as the unique oxidation site of polymer chain. Their radical attack leads to a large variety of degradation products, in particular:

(i) Reactive species formed in addition to $\mathrm{POOH}$, such as alkyl $\mathrm{P}^{\bullet}$ and peroxy radicals $\mathrm{PO}_{2}^{\circ}$.

(ii) Inactive products accumulating in the polymer matrix during the course of oxidation, such as: peroxides POOP, alcohols $\mathrm{P}-\mathrm{OH}$, double-bonds or unsaturations $\mathrm{F}$, and ketones or assimilated carbonyl products $\mathrm{P}=\mathrm{O}$. They are all denoted as secondary oxidation products, since they result from the decomposition of primary oxidation products $(\mathrm{POOH})$.

(iii) Macromolecular events contributing to the modification of polymer physical and mechanical properties, such as chain scissions $S$ on the main polymer chain and crosslinks $B$ (i.e. chemical bridges) between two adjacent polymer chains.

Different stoichiometric coefficients have been introduced as yields for describing the competition between several elementary reactions in balance reactions. For instance, $\gamma_{4}$ and $\gamma_{5}$ are the respective yields of recombination by coupling of alkyl-alkyl and alkyl-peroxy radicals vs. disproportionation in termination steps.

Moreover, $\gamma_{1}$ is the yield in $\beta$-scission (leading to ketones) face to hydrogen abstraction (leading to alcohols) in both unimolecular (1u) and bimolecular initiation steps (1b). For the sake of simplicity, $\gamma_{s}$ accounts for to $\beta$-scissions on the main polymer chain (denoted by $S$ ), which significantly impact the molecular mass, contrarily to $\beta$-scissions on side-chain and end-chain groups which generate small volatile organic compounds.

From a practical point of view, it is more convenient to consider an apparent yield $\gamma_{1}{ }^{\text {app }}$ for carbonyl products owing to the high uncertainty on their nature and the value of their molar extinction coefficients at $1713 \mathrm{~cm}^{-1}$.

Finally, it is likely that formalizing the competition between propagation (by hydrogen abstraction) and recombination of alkoxy radicals through a cage reports the thermolabile feature of peroxide bridges.

\subsubsection{Photochemically induced initiation processes}

To account for the effect of UV-light, several important photoinduced reactions have to be considered. Since UV-light is an extrinsic source of radicals, the decomposition reactions of all photosensitive species (i.e. chromophores) identified as cleavable have been introduced into the previous CLMS. These reactions are: (i) the photolysis of hydroperoxides, through the scission of $\mathrm{O}-\mathrm{O}$ bond, (ii) the analogous photolysis of peroxide bridges, since, these latter are still more photosensitive than hydroperoxides, (iii) the homolytic scission (in $\alpha$-position) of ketones, also named Norrish 1 reaction, (iv) and the Norrish 2 reaction, through a concerted mechanism involving a six centers rearrangement.

These reactions are all the more relevant to consider that they have been identified as the main sources of chain-scission and thus, appear as critical in order to simulate the subsequent changes in mechanical and aspect properties.

It is noteworthy that the amount of ketones has been properly formalized here by differentiating them from other carbonyl species, since they do not accumulate in the polymer matrix anymore: ketones are now submitted to photolysis processes (in particular, Norrish 1 reaction) because they absorb UV-light above $290 \mathrm{~nm}$, unlike other carbonyl products such as esters or carboxylic acids. Besides, it has been necessary to differentiate middle-chain from end-chain ketones (i.e. methyl ketones), denoted as ketones $\mathrm{A}$ $\left(K_{\mathrm{A}}\right)$ and ketones $\mathrm{B}\left(K_{\mathrm{B}}\right)$ respectively, since their formation (by photolysis of alkyl- and hydro-peroxides) and decomposition (by Norrish 1 and 2 reactions) do not involve the same scission position along the polymer chain. Indeed, ketones $K_{\mathrm{B}}$ are formed by $\beta$-scissions on the main polymer chain, whereas ketones $K_{\mathrm{A}}$ result from $\beta$-scissions on side-chain methyl groups. Their respective yields were written $\gamma_{1}^{\prime}$ and $\gamma_{1}^{\prime \prime}$. They satisfy the following equality: $\gamma_{1}=\gamma_{1}^{\prime}+\gamma_{1}^{\prime \prime}$. Moreover, only Norrish type reactions on ketones $K_{\mathrm{A}}$ lead to scissions on main polymer chain, unlike those on ketones $K_{\mathrm{B}}$ which induce scissions near chain extremities.

Hydroperoxides decomposition can be written through the following sequence of elementary chemical steps:

$\mathrm{POOH}+\mathrm{h} v \rightarrow \mathrm{PO}^{\bullet}+\mathrm{HO}^{\bullet}\left(\mathrm{k}_{1 \mathrm{~h}}\right)$

$\gamma_{1}^{\prime} \mathrm{PO}^{\bullet} \rightarrow \gamma_{1}^{\prime} K_{\mathrm{A}}+\mathrm{P}_{\text {nontertiary }}^{\cdot}$

$\gamma_{1}^{\prime \prime} \mathrm{PO}^{\bullet} \rightarrow \gamma_{1}^{\prime \prime} K_{\mathrm{B}}+\mathrm{P}_{\text {nontertiary }}^{\cdot}+\gamma_{\mathrm{S}} S$

$\mathrm{P}_{\text {nontertiary }}^{\bullet}+\mathrm{PH} \rightarrow \mathrm{PH}_{\text {nontertiary }}+\mathrm{P}^{\bullet}$

$\left(1-\gamma_{1}^{\prime}-\gamma_{1}^{\prime \prime}\right) \mathrm{PO}^{\bullet}+\mathrm{PH} \rightarrow\left(1-\gamma_{1}^{\prime}-\gamma_{1}^{\prime \prime}\right) \mathrm{POH}+\mathrm{P}^{\bullet}$

$\mathrm{HO}^{\bullet}+\mathrm{PH} \rightarrow \mathrm{H}_{2} \mathrm{O}+\mathrm{P}^{\bullet}$

Then, the balance reaction is:

(1h) $\mathrm{POOH}+\mathrm{h} \nu \rightarrow 2 \mathrm{P}^{\bullet}+\left(1-\gamma_{1}^{\prime}-\gamma_{1}^{\prime \prime}\right) \mathrm{P}-\mathrm{OH}+\gamma_{1}^{\prime} K_{\mathrm{A}}+\gamma_{1}^{\prime \prime} K_{\mathrm{B}}+\mathrm{H}_{2} \mathrm{O}+$ $\gamma_{\mathrm{s}} \mathrm{S}(-2 \mathrm{PH})\left(\mathrm{k}_{1 \mathrm{~h}}\right)$

Its rate is governed by the slowest step, i.e. the scission of $\mathrm{O}-\mathrm{O}$ bond. Thus, hydroperoxides decomposition by UV-light is assumed to be exclusively unimolecular. Indeed, from a photophysical point of view, the photo-induced bimolecular decomposition of hydroperoxides would apply to a termolecular process whose probability of occurrence would be very low in most of cases. This assumption will be discussed further in a section dedicated to termolecular processes in general.

Regarding all peroxide type species, the photolysis of peroxide bridges must be also considered. Indeed, these latter are known to be more photosensitive (due to their higher molar extinction coefficient) than and almost as cleavable as hydroperoxides [1,3]. The sequence of elementary chemical steps is similar as for hydroperoxides, except that photolysis generates two alkoxy 


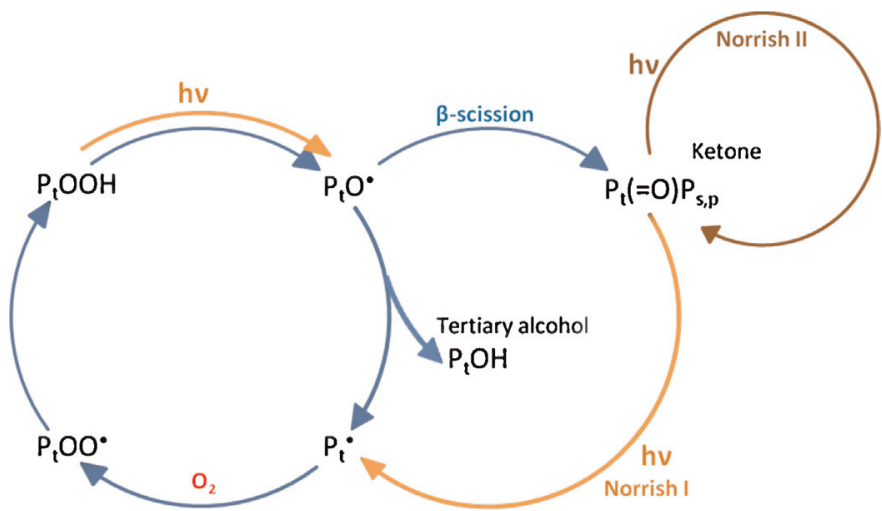

Fig. 1. Multi-closed-loops mechanistic scheme for the photothermal oxidation of polypropylene.

radicals instead of one alkoxy and one hydroxy radicals. Thus, the writing of the balance reaction is immediate:

$\left(1_{\mathrm{p}}\right) \quad \mathrm{POOH}+\mathrm{h} \nu \rightarrow 2\left(1-\gamma_{1}^{\prime}-\gamma_{1}^{\prime \prime}\right) \mathrm{P}-\mathrm{OH}+2 \gamma_{1}^{\prime} K_{\mathrm{A}}+2 \gamma_{1}^{\prime \prime} K_{\mathrm{B}}+2 \gamma_{\mathrm{s}} S$ $(-2 \mathrm{PH})\left(\mathrm{k}_{1 \mathrm{p}}\right)$

Norrish 1 reaction generates an acyl radical which is assumed to undergo a total decarbonylation to give finally an alkyl radical.

$K_{\mathrm{A}}+\mathrm{h} \nu \rightarrow \mathrm{P}=\mathrm{O}^{\bullet}+$ P.nontertiary $+\mathrm{S}\left(\mathrm{k}_{\mathrm{N} 1 \mathrm{~A}}\right)$

$K_{\mathrm{B}}+\mathrm{h} v \rightarrow \mathrm{nP}=\mathrm{O}^{\bullet}+\mathrm{P}^{\bullet}$ nontertiary $\left(\mathrm{k}_{\mathrm{N} 1 \mathrm{~B}}\right)$

$\mathrm{P}=\mathrm{O}^{\bullet} \rightarrow \mathrm{P}^{\bullet}$ nontertiary $+\mathrm{CO} /$

$\mathrm{P}^{\bullet}$ nontertiary $+\mathrm{PH} \rightarrow \mathrm{P}^{\bullet}+\mathrm{PH}$ nontertiary

Hence, the corresponding balance reactions for ketones $\mathrm{A}$ and $\mathrm{B}$ are:

$(\mathrm{N} 1 \mathrm{~A}) K_{\mathrm{A}}+\mathrm{h} v \rightarrow 2 \mathrm{P}^{\bullet}+\mathrm{CO} \nearrow+\mathrm{S}(-2 \mathrm{PH})\left(\mathrm{k}_{\mathrm{N} 1 \mathrm{~A}}\right)$

$(\mathrm{N} 1 \mathrm{~B}) K_{\mathrm{B}}+\mathrm{h} v \rightarrow 2 \mathrm{P}+\mathrm{CO} /(-2 \mathrm{PH})\left(\mathrm{k}_{\mathrm{N} 1 \mathrm{~B}}\right)$

Norrish 2 reaction consists in a six-membered mechanism which does not produce radicals, but transforms the middle-chain ketone $K_{\mathrm{A}}$ into an end-chain ketone $K_{\mathrm{B}}$ (methyl ketone). In contrast, it eliminates ketone $K_{\mathrm{B}}$ in the form of a volatile product (acetone).

$(\mathrm{N} 2 \mathrm{~A}) K_{\mathrm{A}}+\mathrm{h} v \rightarrow K_{\mathrm{B}}+\mathrm{F}+\mathrm{S}\left(\mathrm{k}_{\mathrm{N} 2 \mathrm{~A}}\right)$

$(\mathrm{N} 2 \mathrm{~B}) K_{\mathrm{B}}+\mathrm{h} v \rightarrow \mathrm{F}+\mathrm{Ac} \nearrow\left(\mathrm{k}_{\mathrm{N} 2 \mathrm{~B}}\right)$

where $\mathrm{F}$ designates a vinylene double bond.

Therefore, the general mechanistic scheme for the photothermal oxidation of polypropylene potentially involves several closed-loops, since peroxide type species and ketones are all 'critical species' which decompose into radicals meanwhile they are produced during the oxidation process. Thereafter, it will be called "multi-closed loops mechanistic scheme" (MCLMS) (Fig. 1).

\subsection{Kinetics in photochemistry}

\subsubsection{Quantum theory}

According to the first law of photochemistry (Grotthus, 1817 and Drapper, 1843), only the UV-light absorbed by a molecule can lead to photochemical changes. According to the second law of photochemistry (Stark-Einstein, 1908), this is a one-quantum process. In the case of hydroperoxides photolysis, the absorption of light is attributed to the forbidden $\sigma^{*} \leftarrow \mathrm{n}$ transition from a nonbonding orbital to an anti-bonding valence orbital. As a consequence, the excited state is not stable and its absorption spectrum (i.e. the spectral distribution of molar extinction coefficient) is very diffuse. This result thereby explained both the high cleavability and the relatively low value of the molar extinction coefficient of hydroperoxides. At this stage, it is valuable to precise that the molar extinction coefficient accounts for the probability that an incident quantum will be absorbed by a molecule after a collision (the reader may refer to Calvert and Pitts [32] or Ranby and Rabek [33] for more details).

In the case of ketones, the main absorption band, whose maximum appears between 280 and $320 \mathrm{~nm}$ in the UV-vis range, corresponds to the excitation of an electron from a non-bonding to an anti-bonding orbital ( $\pi^{*} \leftarrow \mathrm{n}$ transition), mainly localized on the carbonyl group. The absorption in the far UV-range corresponds to the $\pi^{*} \leftarrow \pi$ transition for the excited electron, which is delocalized over the entire molecule.

Once excited from ground state $S_{0}$ to singlet excited state $S_{1}$, the molecule can desexcite though different elementary steps (bond dissociation, intramolecular isomerization, fluorescence, phosphorescence, internal conversion or vibrational (i.e. non-radiative) relaxation), denoted as kinds of primary processes since they result from the immediate effect of light on the absorbing molecule. In contrast, the secondary processes consist in subsequent chemical reactions undergone by excited molecules or in the production of radicals by the primary processes. It is thus possible to calculate the efficiency, i.e. the probability of occurrence, of the bond dissociation (by photolysis) compared with other competitive primary processes. Since it is a one-quantum mechanism, the sum of the quantum yields of all these elementary photochemical processes is equal to unity (Stark-Bodenstein, 1913). On the contrary, when secondary processes are involved, the quantum yield of this phenomenon can be greater than unity. This is the case, for instance, for chain scission processes.

\subsubsection{Formalism and calculation of the rate constants of photo- induced reactions}

The temperature dependence of thermal oxidation is described by applying the Arrhenius law to the rate constant $k_{i}$ of each elementary reaction (i):

$k_{\mathrm{i}}=k_{\mathrm{i}}^{0} \exp \frac{-E \mathrm{a}_{\mathrm{i}}}{\mathrm{RT}}$

with $k_{\mathrm{i}}^{0}$ the pre-exponential factor and $E \mathrm{a}_{\mathrm{i}}$ the activation energy.

Analogously, a suitable formalism must be found to report the kinetic dependence of photo-induced reactions with the amount of "radiant" UV-vis energy. According to the quantum theory, the initiation rate by a given photosensitive species $X$ (i.e. a chromophore) can be written as the product of the energy absorbed by the photolysis efficiency, i.e. the probability that an absorbed photon triggers the chemical bond dissociation:

$\left.\frac{\mathrm{d}[X]}{\mathrm{d} t}\right\rfloor^{\text {photolysis }}=-\Phi(\lambda)_{X} \times I_{\mathrm{abs}_{v}}$

with $[X]$ the concentration of the chemical species $X$ (in $\left.\mathrm{mol} \mathrm{L}^{-1}\right), I_{\mathrm{abs}}$ the volumic absorbed energy (in Einstein $\mathrm{L}^{-1} \mathrm{~s}^{-1}$ ), and $\Phi(\lambda)_{X}$ the quantum yield of photolysis efficiency (in mol Einstein $^{-1}$, dimensionless).

This energy absorbed by the photosensitive species consists in the overall quanta energy satisfying the authorized electronic transitions. It can be thus deduced by calculating the overlap between the spectral distribution of molar extinction coefficient 
and the energy emitted by the UV-light source. It can be written as:

$I_{\mathrm{abs}_{v}}=\int_{\lambda_{\min }}^{\lambda_{\max }} \frac{\ln (10) E(\lambda) \lambda \varepsilon_{X}(\lambda) \Delta z[X]}{10 N_{\mathrm{a}} \text { he } \Delta z} \mathrm{~d} \lambda$

with $E(\lambda)$ the spectral irradiance of the light source including filters (in $\mathrm{W} \mathrm{m}^{-2} \mathrm{~nm}^{-1}$ ), $N_{\mathrm{a}}$ the Avogadro's number, $h$ the Planck constant equal to $6.623 \times 10^{-34} \mathrm{Js}, c$ the light celerity (in $\mathrm{ms}^{-1}$ ), $\lambda$ the wavelength (in $m), \varepsilon_{X}(\lambda)$ the spectral distribution of the molar extinction coefficient (in $\left.\mathrm{L} \mathrm{mol}^{-1} \mathrm{~cm}^{-1}\right),[X]$ the concentration of the photosensitive species $X$ (in $\mathrm{mol} \mathrm{L}^{-1}$ ), and $\Delta z$ the sample thickness (in $\mathrm{m}$ ).

Since the concentration $[X]$ is a separate variable, it is possible to calculate the spectral overlap integral of light absorption $J_{X}$ (in Einstein $\left.\mathrm{mol}^{-1} \mathrm{~s}^{-1}\right)$, chosen here as the relevant criterion independent of concentration to describe oxidation, and defined as:

$J_{X}=\frac{I_{\mathrm{abs}}}{[X]}=\int_{\lambda_{\min }}^{\lambda_{\max }} \frac{\ln (10) E(\lambda) \lambda}{10 N_{\mathrm{a}} \mathrm{hc}} \varepsilon_{X}(\lambda) \mathrm{d} \lambda$

It is thus noteworthy that the product $\Phi \times \mathrm{J}$ is homogeneous to the rate constant of a unimolecular decomposition (i.e. expressed in $\mathrm{s}^{-1}$ ). If $\mathrm{k}_{1 x}$ designates the corresponding rate constant, it can be thus written, for a given chemical species $X: \mathrm{k}_{1 X}=\Phi_{X} \times J_{X}$.

\subsubsection{Domains of validity}

Thus, the presented theory of quantum photochemistry only deals with the "bimolecular" interaction of a UV-light quantum with a molecule, i.e. an unimolecular photo-induced bond dissociation. In other words, this is not suitable for treating the case of termolecular reactions (involving two molecules and a quantum). The probability of collision between three species is usually considered as very low, but could occur in several cases: two molecules would be associated in a relative stable complex, whose lifetime would be long enough to allow a quantum absorption. This is all the more likely for high density (concentration) of quanta and so, high irradiance. Applying the quantum theory would be theoretically possible by formalizing the transient state for a molecule in a complex, but the absorption features of such an intermediate species are unclear and experimental data are very scarce.

The other complication for high UV-light intensities would be the occurrence of biphotonic (or multiphotonic) excitations, which consist in a quantum absorption by a molecule already excited by a previous absorption. Such a phenomenon is considered as negligible for sufficiently low irradiances regarding at the short lifetime of excited states. Admittedly, it remains possible to consider the notion of three-states quantum yields in order to account for the excitation of the excited states higher than $\mathrm{S}_{1}$, but this problem would be practically out-of-reach because of the overcomplexity of phenomena. As a result, it will be considered that the validity of the kinetic model is restricted to monophotonic excitations.

\subsubsection{Application to kinetic modeling}

Solving a problem of photothermal oxidation requires beforehand the determination of unknown kinetic parameters, in particular $\Phi$ and $J$, as well as the setting of several simplifying assumptions:

(i) The quantum yield must be independent of temperature. This is theoretically true for primary processes according to Calvert and Pitts [32]. Guillet et al. [34] measured the temperature dependence of the quantum yield of Norrish type reactions. They found an activation energy of $3.5 \mathrm{~kJ} \mathrm{~mol}^{-1}$ for $\phi_{\mathrm{N} 2}$ in the case of 8-pentadecanone, which is a rather moderate value. They observed activation energies of 20 and $21.7 \mathrm{~kJ} \mathrm{~mol}^{-1}$ for $\phi_{\mathrm{N} 2}$ in the case of 8-pentanedecanone and polyethylene-cocarbon monoxide (PE-Co-CO) respectively. This latter temperature dependence was presumably assigned to a radical diffusion facilitated at high temperature, thereby promoting cleavage according to the Frank-Rabinowitch's principle (cage effect). Besides, it is noteworthy that this quantum yield was measured basing on the emission of carbon monoxide, whereas decarbonylation is expected to be thermally activated [35].

(ii) The quantum yield must be independent of the molecular weight of photosensitive species. Otherwise, it would change with the amount of chain scissions and thus, would be timedependent. This assumption has been investigated by Guillet et al. in the case of Norrish 1 reaction for model compounds, again basing on the yield in carbon monoxide [34,36]. They found no change with molar mass in the case of molecules containing more than 30 carbon atoms.

The quantum yield must remain unchanged along time, i.e. must be independent of the conversion degree of oxidation. To apprehend this issue, it is relevant to carefully study photochemical processes, especially Norrish type reactions. For instance, Norrish 2 rearrangement would happen from both singlet $S_{1}$ and triplet $\mathrm{T}_{1}$ excited states [37]. In a non-polar solvent, such as hexane, this reaction would be twice more likely to occur from $T_{1}$ than $S_{1}$ for both aliphatic and acyclic ketones according to studies made on poly(ethylene-co-carbon monoxide) [37] and molecular model compounds $[38,39]$. However, only rearrangements from singlet state would be independent of the solvent polarity. These results suggest that the quantum yield for the Norrish 2 reaction is prone to change with the polymer polarity, thus restraining the validity of the kinetic model to low conversion degrees of oxidation for which polarity changes are negligible.

- Theoretically, the quantum yield is wavelength dependent, so its spectral distribution $\Phi(\lambda)$ should be considered. This dependence can be explained, for instance, by the settlement of higher excited states than $S_{1}$. Their direct determination can be tentatively performed on model compounds by using monochromatic UVlight sources, for instance lasers, in the case of flash photolysis techniques. These spectral distributions have been compiled for tert-butyl hydroperoxide [40] and various ketonic products $[41,42]$, as depicted in figures B1 and B2 in Supporting information. The photolysis of macromolecular photosensitive species could also be investigated by using other types of monochromatic UV-light source, such as LED, or polychromatic sources with filters of narrow bandwidth $[43,44]$. In practice, it is more convenient to consider that the quantum yield is constant in the whole spectral range, i.e. that its spectral distribution can be neglected. Such a hypothesis is not unrealistic, considering that the efficient wavelength range is restricted to few decades of nanometers in current photochemical aging conditions.

\subsection{Model equations}

\subsubsection{System of differential equations (SDE)}

The MCLMS can be translated into a system of ordinary differential equations (SDE) describing the local concentration changes in relevant chemical species by using the classical concepts of chemical kinetics. This SDE can be written as (Eq. $(6-14))$ :

$\mathrm{d}\left[\mathrm{P}^{\bullet}\right] / \mathrm{d} t=2 \mathrm{k}_{\mathrm{lu}} \quad[\mathrm{POOH}]+\mathrm{k}_{\mathrm{lb}}[\mathrm{POOH}]^{2}-\mathrm{k}_{2}\left[\mathrm{P}^{\bullet}\right]\left[\mathrm{O}_{2}\right]+\mathrm{k}_{3}\left[\mathrm{PO}_{2}^{\bullet}\right][\mathrm{PH}]$ $-2 \mathrm{k}_{4}\left[\mathrm{P}^{\bullet}\right]^{2}-\mathrm{k}_{5}\left[\mathrm{P}^{\bullet}\right]\left[\mathrm{PO}_{2}^{\bullet}\right]+2 \mathrm{k}_{6 \mathrm{~d}}[\mathrm{PO} \bullet \mathrm{OP}]+2 \varphi_{\mathrm{POOH}} J_{\mathrm{POOH}}[\mathrm{POOH}]+2$ $\varphi_{\mathrm{N} 1 \mathrm{a}} J_{\mathrm{K}}\left[K_{\mathrm{A}}\right]+2 \varphi_{\mathrm{N} 1 \mathrm{~b}} J_{\mathrm{K}}\left[K_{\mathrm{B}}\right]+2 \varphi_{\mathrm{POOP}} J_{\mathrm{POOP}}[\mathrm{POOP}](6)$ 
$\begin{aligned} \frac{\mathrm{d}\left[\mathrm{PO}_{2}^{\cdot}\right]}{\mathrm{d} t} & =\mathrm{k}_{1 b}[\mathrm{POOH}]^{2}+\mathrm{k}_{2}\left[\mathrm{P}^{\bullet}\right]\left[\mathrm{O}_{2}\right]-\mathrm{k}_{3}\left[\mathrm{PO}_{2}^{\cdot}\right][\mathrm{PH}]-\mathrm{k}_{5}\left[\mathrm{P}^{\bullet}\right]\left[\mathrm{PO}_{2}^{\cdot}\right] \\ & -2 \mathrm{k}_{6 \mathrm{a}}\left[\mathrm{PO}_{2}^{\cdot}\right]^{2}\end{aligned}$

$\mathrm{d}[\mathrm{POOH}] / \mathrm{d} t=-\mathrm{k}_{\mathrm{lu}}[\mathrm{POOH}]-2 \mathrm{k}_{\mathrm{lb}}[\mathrm{POOH}]^{2}+\mathrm{k}_{3}\left[\mathrm{PO}_{2}^{\circ}\right][\mathrm{PH}]$

$+\left(1-\gamma_{5}\right) \mathrm{k}_{5}\left[\mathrm{P}^{\bullet}\right]\left[\mathrm{PO}_{2}^{\circ}\right]-\varphi_{\mathrm{POOH}} J_{\mathrm{POOH}}[\mathrm{POOH}]$

$\mathrm{d}[\mathrm{PH}] / \mathrm{d} t=-2 \mathrm{k}_{\mathrm{lu}}[\mathrm{POOH}]-\mathrm{k}_{\mathrm{lb}}[\mathrm{POOH}]^{2}-\mathrm{k}_{3}\left[\mathrm{PO}_{2}^{\circ}\right][\mathrm{PH}]+\left(1-\gamma_{4}\right)$

$\mathrm{k}_{4}\left[\mathrm{P}^{\bullet}\right]^{2}-2 \mathrm{k}_{6 \mathrm{~d}}\left[\mathrm{PO} \bullet \mathrm{OP}^{\circ}\right]$

$-2 \varphi_{\mathrm{POOH}} J_{\mathrm{POOH}}[\mathrm{POOH}]-2 \varphi_{\mathrm{N} 1} J_{\mathrm{K}}\left[K_{\mathrm{A}}\right]-2 \varphi_{\mathrm{N} 1} J_{\mathrm{K}}\left[K_{\mathrm{B}}\right]-2$

$\varphi_{\text {POOPJPOOP }}[\mathrm{POOP}](9)$

$\frac{\mathrm{d}\left[\mathrm{PO}^{\circ} \mathrm{OP}\right]}{\mathrm{d} t}=\mathrm{k}_{60}\left[\mathrm{PO}_{2}^{*}\right]^{2}-\left(\mathrm{k}_{6 b}+\mathrm{k}_{6 d}\right)\left[\mathrm{PO}^{\circ} \mathrm{OP}\right]$

${ }^{\partial}\left[\mathrm{O}_{2}\right] /{ }_{\partial} t=\mathrm{D}_{\mathrm{O}_{2}}{ }^{2}\left[\mathrm{O}_{2}\right] / \partial z^{2}-\mathrm{k}_{2}\left[P^{\bullet}\right]\left[\mathrm{O}_{2}\right]-\mathrm{k}_{6 a}\left[\mathrm{PO}_{2}^{\cdot}\right]^{2}$

$\mathrm{d}\left[K_{\mathrm{A}}\right] / \mathrm{d} t=-\gamma_{1 \mathrm{a}}\left(\mathrm{k}_{\mathrm{lu}}[\mathrm{POOH}]+\mathrm{k}_{\mathrm{lb}}[\mathrm{POOH}]^{2}+2 \mathrm{k}_{6 \mathrm{~d}}[\mathrm{PO} \bullet \mathrm{OP}]+\right.$ $\left.\varphi_{\mathrm{POOH}} J_{\mathrm{POOH}}[\mathrm{POOH}]+2 \varphi_{\mathrm{POOP}} J_{\mathrm{POOP}}[\mathrm{POOP}]\right)$

$-\varphi_{\mathrm{N} 1} J_{\mathrm{K}}\left[K_{\mathrm{A}}\right]-$

$\varphi_{\mathrm{N} 2} J_{\mathrm{K}}\left[K_{\mathrm{A}}\right]$

$\mathrm{d}\left[K_{\mathrm{B}}\right] / \mathrm{d} t=-\gamma_{1 \mathrm{~b}}\left(\mathrm{k}_{\mathrm{lu}}[\mathrm{POOH}]+\mathrm{k}_{\mathrm{lb}}[\mathrm{POOH}]^{2}+2 \mathrm{k}_{6 \mathrm{~d}}[\mathrm{PO} \cdot \bullet \mathrm{OP}]\right.$

$\left.+\varphi_{\mathrm{POOH}} J_{\mathrm{POOH}}[\mathrm{POOH}]+2 \varphi_{\mathrm{POOP}} J_{\mathrm{POOP}}[\mathrm{POOP}]\right)$

$-\varphi_{\mathrm{N} 1} J_{\mathrm{K}}\left[K_{\mathrm{B}}\right]-\varphi_{\mathrm{N} 2} J_{\mathrm{K}}\left[K_{\mathrm{B}}\right]+\varphi_{\mathrm{N} 2} J_{\mathrm{K}}\left[K_{\mathrm{A}}\right](13)$

$\frac{\mathrm{d}[\mathrm{POOP}]}{\mathrm{d} t}=\gamma_{5} \mathrm{k}_{5}\left[\mathrm{P}^{\bullet}\right]\left[\mathrm{PO}_{2}^{\cdot}\right]+\mathrm{k}_{6 b}\left[\mathrm{PO}{ }^{\circ} \mathrm{OP}\right]-\varphi_{\mathrm{POOP}} J_{\mathrm{POOP}}[\mathrm{POOP}]$

where $\left[\mathrm{P}^{\bullet}\right],\left[\mathrm{PO}_{2}^{\circ}\right],[\mathrm{POOH}],[\mathrm{PH}],[\mathrm{PO} \bullet \bullet \mathrm{OP}],\left[\mathrm{O}_{2}\right], K_{\mathrm{A}}, K_{\mathrm{B}}$ and [POOP] are the respective concentrations in alkyl and peroxy radicals, hydroperoxides, tertiary $\mathrm{CH}$ groups, cage paired alkoxy radicals, oxygen, ketones of type A (middle-chain ketones) and B (end-chain or methyl ketones), and peroxide bridges. $D_{\mathrm{O}_{2}}$ is the coefficient of oxygen diffusion into the semi-crystalline polymer, here considered constant and independent of time (i.e. of conversion degree of oxidation).

Although the present study is only focused on homogeneously oxidized iPP films, the Fick's second law (for oxygen diffusion) has been directly introduced into the oxygen balance equation (i.e. Eq. (11)) in order to take into account the possible effects, even small, of the diffusion-limited oxidation (DLO).

From this SDE, it is also possible to calculate the local concentrations in chain scissions $S$ and crosslinks $B$ (covalent bridges), or even in double bonds $\mathrm{F}$ (unsaturations):

$\mathrm{d} S / \mathrm{d} t=\gamma_{1 \mathrm{~b}}\left(\mathrm{k}_{\mathrm{lu}}[\mathrm{POOH}]+\mathrm{k}_{\mathrm{lb}}[\mathrm{POOH}]^{2}+2 \mathrm{k}_{6 \mathrm{~d}}[\mathrm{PO} \cdot \bullet \mathrm{OP}]\right.$

$\left.+\varphi_{\mathrm{POOH}} J_{\mathrm{POOH}}[\mathrm{POOH}]+2 \varphi_{\mathrm{POOP}} J_{\mathrm{POOP}}[\mathrm{POOP}]\right)+\varphi_{\mathrm{N} 1} J_{\mathrm{K}}\left[K_{\mathrm{A}}\right]$

$+\varphi_{\mathrm{N} 2} J_{\mathrm{K}}\left[K_{\mathrm{A}}\right](15)$

$\begin{aligned} \frac{\mathrm{d} B}{\mathrm{~d} t} & =\gamma_{4} \mathrm{k}_{4}\left[\mathrm{P}^{\cdot}\right]^{2}+\gamma_{5} \mathrm{k}_{5}\left[\mathrm{P}^{\bullet}\right]\left[\mathrm{PO}_{2}^{\cdot}\right]+\mathrm{k}_{6 b}\left[\mathrm{PO}^{\cdot} \mathrm{OP}\right] \\ & -\varphi_{\mathrm{POOP}} J_{\mathrm{POOP}}[\mathrm{POOP}]\end{aligned}$

$\frac{\mathrm{d} F}{\mathrm{~d} t}=\gamma_{4} \mathrm{k}_{4}\left[\mathrm{P}^{\bullet}\right]^{2}+\gamma_{5} \mathrm{k}_{5}\left[\mathrm{P}^{\bullet}\right]\left[\mathrm{PO}_{2}^{\cdot}\right]+\varphi_{N 2} J_{\mathrm{K}}\left[K_{\mathrm{A}}\right]+\varphi_{N 2} J_{\mathrm{K}}\left[K_{\mathrm{B}}\right]$

\subsubsection{Initial and boundary conditions}

Initial conditions are the same throughout the sample thickness. Thus, at $t=0$, and $\forall z \in[0$; L]:

$\left[\mathrm{P}^{\bullet}\right](0, z)=\left[\mathrm{PO}_{2}^{\bullet}\right](0, z)=[\mathrm{PO} \bullet \bullet \mathrm{OP}](0, z)=0 \mathrm{~mol} \mathrm{~L}^{-1}$

$[\mathrm{PH}](0, z)=[\mathrm{PH}]_{0} \approx 20.3 \mathrm{~mol} \mathrm{~L}^{-1}$

$[\mathrm{POOH}](0, z)=[\mathrm{POOH}]_{0}=4 \times 10^{-3} \mathrm{~mol} \mathrm{~L}^{-1}$
$[\mathrm{P}=\mathrm{O}](0, z)=[\mathrm{P}=\mathrm{O}]_{0}=10^{-4} \mathrm{~mol} \mathrm{~L}^{-1}$

$\left[\mathrm{O}_{2}\right](0, z)=C_{\mathrm{s}}$

Boundary conditions at the film surfaces (i.e. at $z=0$ and $z=\mathrm{L}$ ) are:

$\forall t>0,\left[\mathrm{O}_{2}\right](t, 0)=\left[\mathrm{O}_{2}\right](t, \mathrm{~L})=C_{\mathrm{s}}$

with $C_{\mathrm{s}}$ the oxygen concentration (in $\mathrm{mol} \mathrm{L}^{-1}$ ) in the polymer in equilibrium with the atmosphere under an oxygen partial pressure $P_{\mathrm{O}_{2}}$ given by the Henry's law:

$C_{\mathrm{s}}=\mathrm{P}_{\mathrm{O}_{2}} \times \mathrm{S}_{\mathrm{O}_{2}}^{\mathrm{am}}$

where $S_{\mathrm{O}_{2}}^{\mathrm{am}}$ is the coefficient of oxygen solubility in the polymer (in $\mathrm{mol} \mathrm{L}^{-1} \mathrm{~Pa}^{-1}$ ) here taken in the amorphous phase, i.e. only where oxygen is soluble [37,38].

3.3.3. Boundary conditions due to aspects of geometrical optics

Inphotothermal oxidation, oxidation profiles does not results from the unique control of chemical reaction by oxygen diffusion (see Eq.(8)), butalsofrom theUV-lightattenuationin thesamplethickness, also called "screen effect". This effect results from:(i) the opacity of the semi-crystalline polymer, largely due to scattering or diffraction phenomena, (ii) the absorption of light by photosensitive species.

Opacity remains almost constant along the course of oxidation provided that morphology does not undergo noticeable changes (i.e. that chemi-crystallization remains negligible). On the contrary, the light absorption by chromophores increases with the conversion degree of oxidation since, chromophores are oxidation products. In this case, the light attenuation factor is decoupled into a constant component accounting for opacity, i.e. into a wavelength dependent coefficient $\alpha(\lambda)$ of lineic absorption, and a variable component describing the light absorption by chromophores using the Beer-Lambert's law. When only one sample face is exposed to UV-light, it comes:

$\forall \mathrm{t}$,

$$
E_{\mathrm{z}+\mathrm{dz}}(\lambda)=E_{\mathrm{z}}(\lambda)\left[1-\left(\alpha(\lambda)+\ln (10) \sum_{\substack{j \\ \text { chromophoric } \\ \text { species }}} \varepsilon_{j}(\lambda)\left[X_{j}\right]\right) \Delta z\right]
$$

with $E_{\mathrm{z}}(\lambda)$ the spectral irradiance (in $\mathrm{W} \mathrm{m}^{-2} \mathrm{~nm}^{-1}$ ) at a depth $z$ (in $\mathrm{m}^{-1}$ ) beneath the irradiated surface, $\alpha(\lambda)$ the coefficient of lineic absorption (in $\mathrm{m}^{-1}$ ), $\varepsilon_{j}(\lambda)$ the spectral distribution of molar extinction coefficient (in $\mathrm{L} \mathrm{mol}^{-1} \mathrm{~m}^{-1}$ ) and $\left[X_{j}\right]$ the concentration of a given photosensitive species $\mathrm{X}_{j}\left(\right.$ in $\left.\mathrm{mol} \mathrm{L}^{-1}\right)$.

The spectral irradiance on the sample surface exposed to UVlight is equal to the intensity of the light source:

$\forall \mathrm{t}$, for $z=0: E_{z \rightarrow \mathrm{o}}(\lambda)=E_{\lambda}$ source

In a first approach, no reflectance coefficient is introduced, since most of the reflected light would not be specular but rather diffuse, which means that the reflected light would have penetrated in the material depth. These aspects would be discussed in the second part of this study dedicated to thicker specimens and optical phenomena.

\subsubsection{Numerical resolution and computation}

The coupling between oxygen diffusion and its chemical consumption by the polymer in the sample thickness was directly introduced into the SDE by using a finite difference method. The sample thickness was discretized into $\mathrm{N}$-1 elementary sublayers of thickness $\Delta z$. The second derivative of the Fick's second law (for oxygen diffusion) was approximated by a central difference expression. In contrast, the coupling of the SDE with the algebraic 

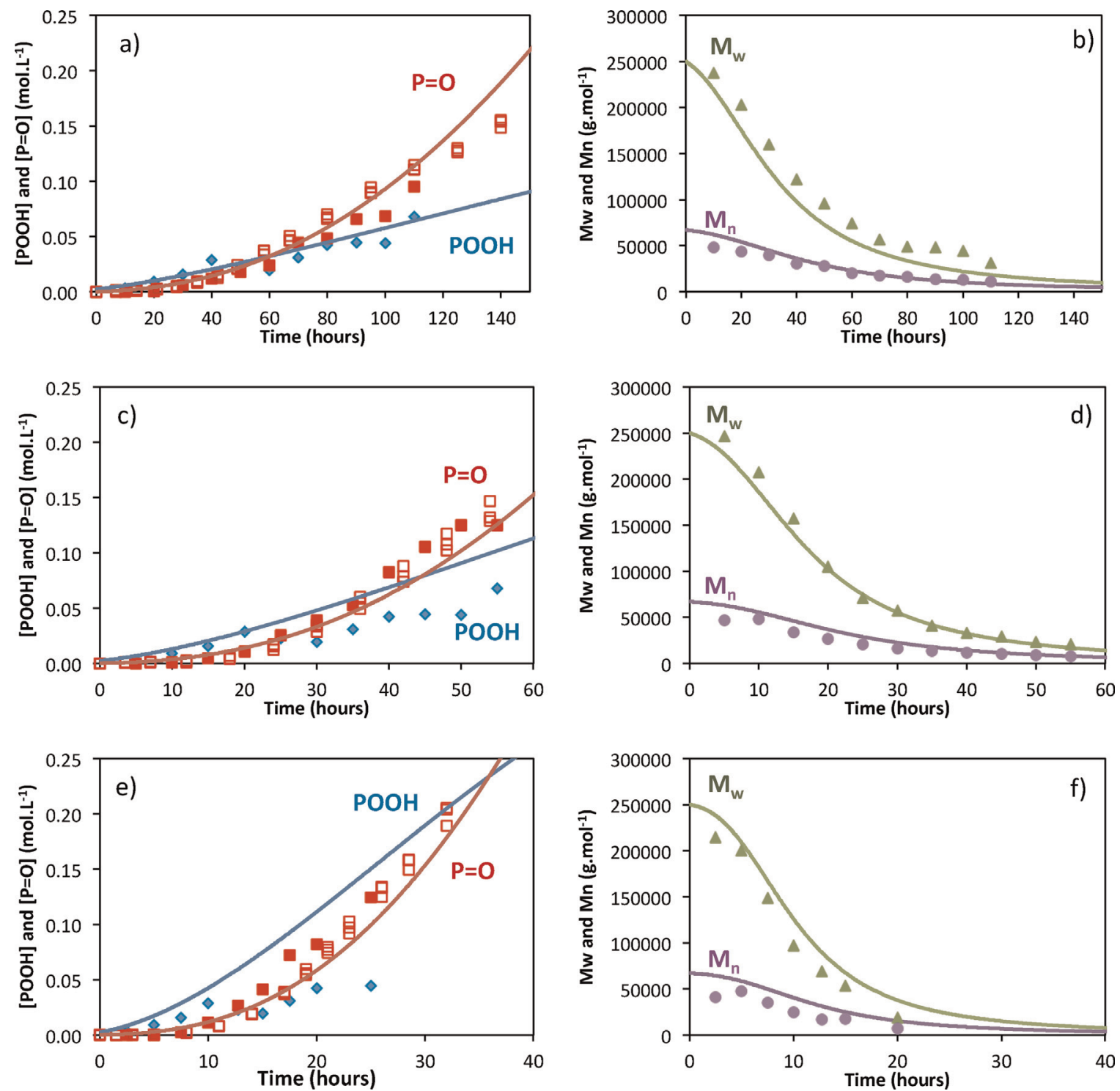

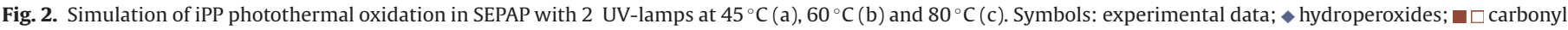
products; $\Delta$ weight and number average molecular masses. Solid lines: kinetic modeling.

equation (19), describing the UV-light attenuation in the sample thickness, is much more complex and cannot be treated with the common Matlab's algorithms recommended for solving stiff problems of chemical kinetics [45]. It requires the use of more suitable algorithms which will be presented in a next publication. In the first approach, it was assumed that the contribution of oxidation products such as chromophores to UV-light attenuation is minority compared with the contribution of opacity (in films of $100 \mu \mathrm{m}$ thick, their respective contributions are less than $0.3 \%$ and $\sim 6 \%$ ). Thus, the SDE was solved numerically, using the ODE15s or ODE23s Matlab's algorithms and applying the initial and boundary conditions given in Eqs. (18) and (19).

Let us remind that the value of oxygen solubility was taken in the amorphous phase. Then, the real concentrations of all chemical species in the semi-crystalline polymer wersee deduced from the concentrations calculated in the amorphous phase by multiplying them by the volumic fraction of amorphous phase $V_{\mathrm{a}}$ :

$V_{\mathrm{a}}=\left(1-\chi_{\mathrm{c}}\right) \times \frac{\rho_{\mathrm{p}}}{\rho_{\mathrm{a}}}$ with $\chi_{\mathrm{c}}$ the crystallinity ratio (as measured by DSC), $\rho_{\mathrm{p}}$ and $\rho_{\mathrm{a}}$ the respective densities of the semi-crystalline polymer $\left(910 \mathrm{~g} \mathrm{~L}^{-1}\right)$ and amorphous phase $\left(854 \mathrm{~g} \mathrm{~L}^{-1}\right)$

Since most of the physico-chemical analyses were done throughout the sample thickness such as, for instance, FTIR monitoring in transmission mode, the global concentrations of all chemical species were averaged from the local values of the $\mathrm{N}-1$ computational sublayers:

$[X]_{\text {global }}(t)=\frac{1}{N-1} \int_{z=0}^{z=N}[X](z, t) \mathrm{d} z$

\section{Experimental results}

\subsection{Photothermal oxidation results}

This work reports a substantial experimental campaign of photothermal oxidation results (Figs. 2-6). These results areunprecedented by the variety of both exposure conditions and multiscale characterizations, all obtained on a unique 

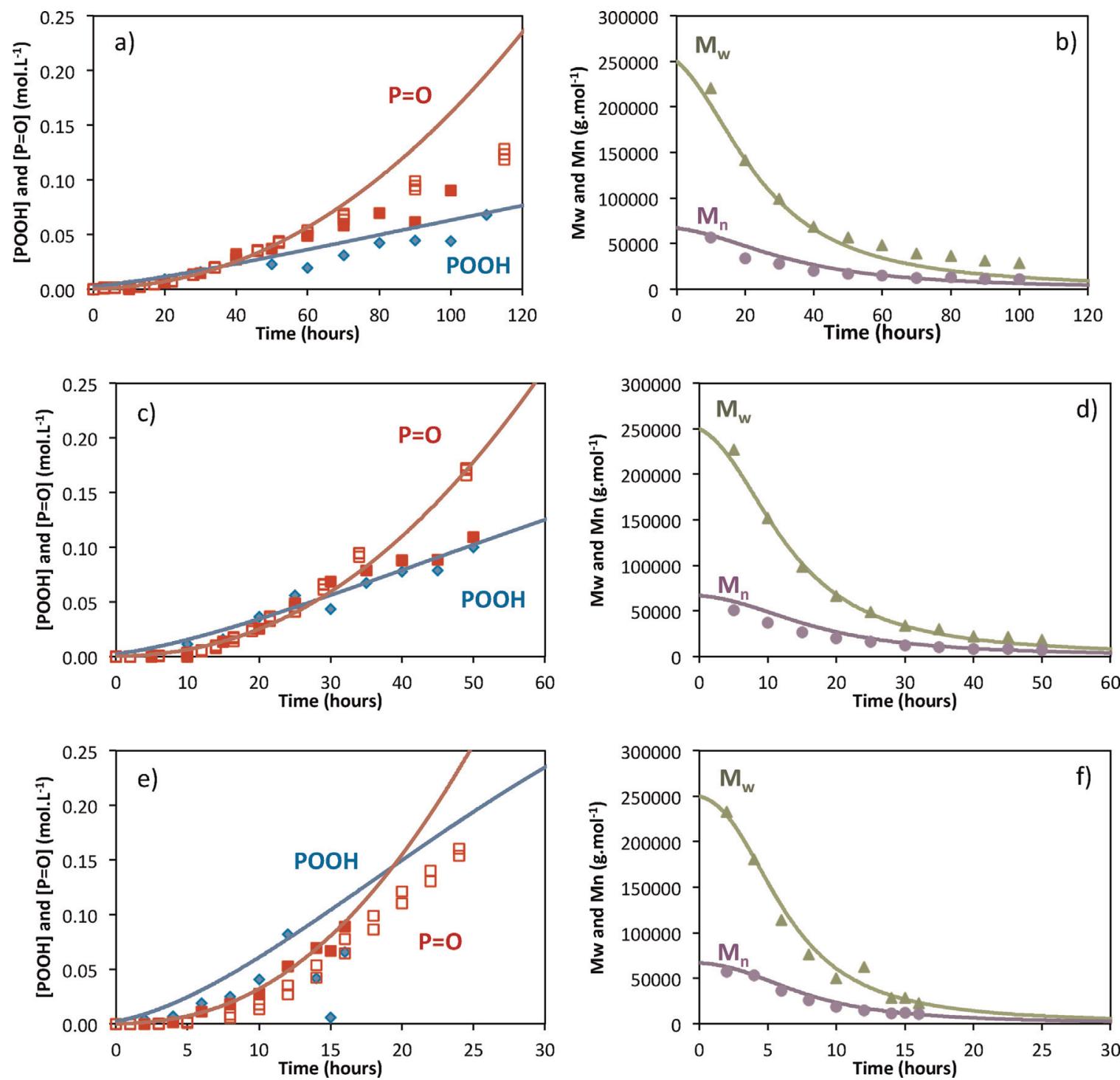

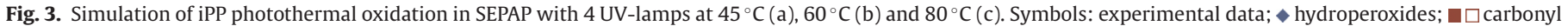
products; $\Delta$ weight and number average molecular masses. Solid lines: kinetic modeling.

reference iPP whose specimens have been cautiously prepared. This last specificity is of a great interest, since it enables to minimize the material variability which might prevent from studying accurately the effect of exposure conditions. The experimental campaign includes exposures under different UVlight sources, namely arc xenon and mercury lamps whose intensities vary in a ratio from 1 to 35 in terms of efficient energy for damaging the material (i.e. in terms of absorbed energy). It also includes the use of complementary analytical techniques, giving an overall view of the oxidation chemistry, in order to follow:

(i) Hydroperoxides involved in the main loop of the MCLMS,

(ii) Carbonyl species involved in the secondary loops of the MCLMS and currently chosen as a relevant oxidation indicator in the literature,

(iii) Double bonds (unsaturations) generated by disproportionation in termination steps.

(iv) And weight and number average molecular masses related to the concentrations of chain scissions $S$ and crosslinks $B$ via the common Saito's equations [46]:
$\overline{M_{\mathrm{w}}}=\left(\frac{S}{2}-2 B+\frac{1}{\overline{M_{\mathrm{w} 0}}}\right)^{-1}$

and

$\overline{M_{\mathrm{n}}}=\left(S-B+\frac{1}{\overline{M_{\mathrm{n} 0}}}\right)^{-1}$

It is relevant to precise here that chain scissions are often considered as responsible for the alteration of both fracture and aspect (in terms of whitening and loss of gloss) properties.

The kinetic modeling approach has been chosen here to study the impact of exposure conditions (i.e. temperature and UV-light) on the relative predominance of the oxidation mechanisms proposed in the literature for describing the photothermal oxidation of iPP.

\subsection{Comparison with pure thermal oxidation}

From Figs. 2-6, several comments can be made on the shape of kinetic curves: 

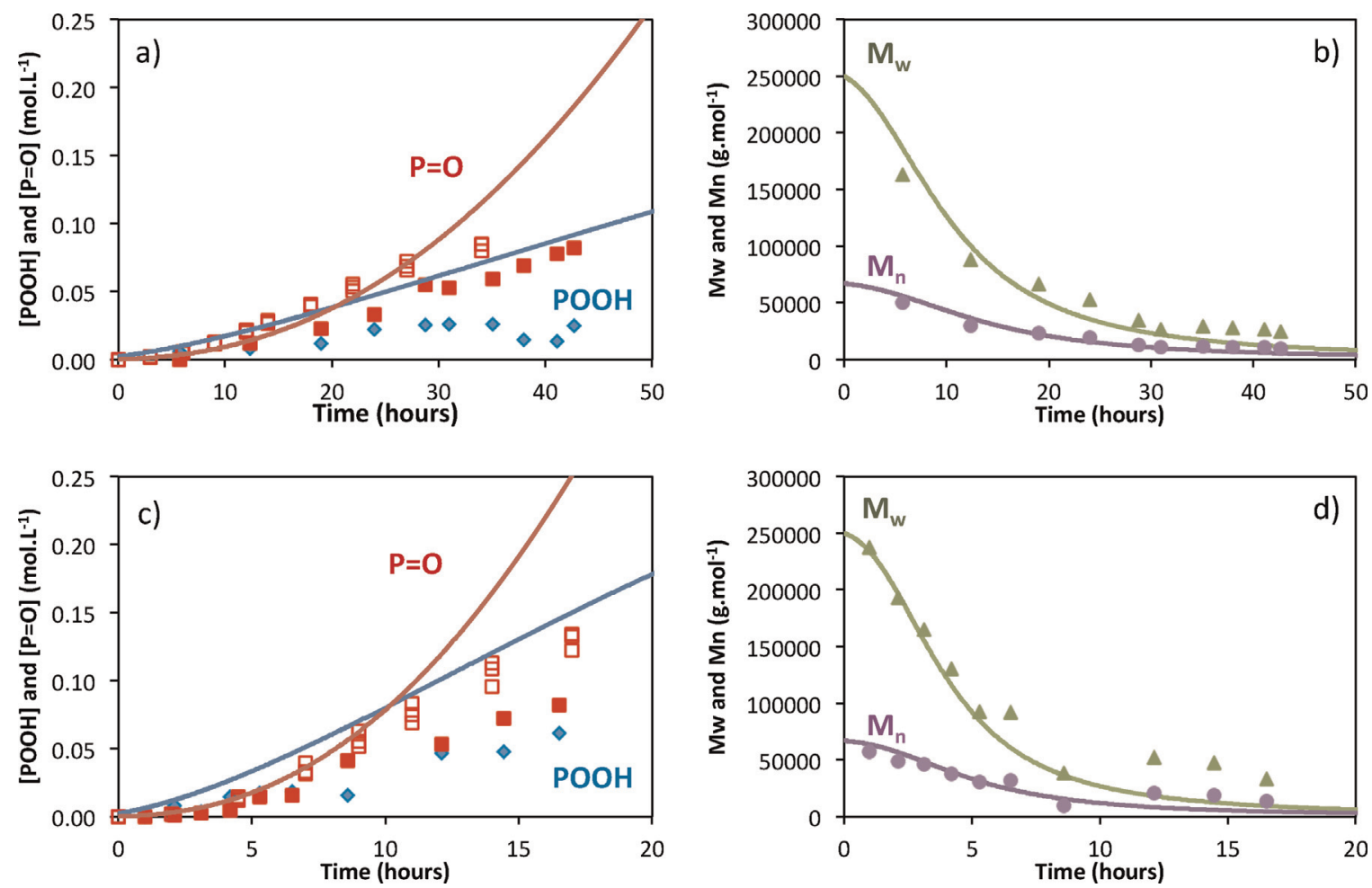

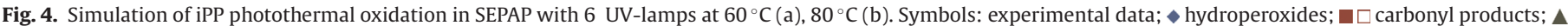
weight and number average molecular masses. Solid lines: kinetic modeling.

(i) Contrarily to pure thermal oxidation at the same temperature, one can observe a very low value, and even sometimes the absence, of induction period. Moreover, the extent of oxidative degradation is an increasing function of both temperature and UV-light intensity (i.e. number of UV-lamps in SEPAP devices), although the impact of temperature seems to be much more pronounced. No doubt, this complex combination between the effects of temperature and UV-light intensity will constitute an important validity criterion for the kinetic model.

(ii) The carbonyls concentration gradually grows with exposure time up to the film embrittlement. This final value corresponds approximately to that found for pure thermal oxidation at the same temperature. This result suggests that ketones photolysis (by Norrish 1 and 2 reactions) would be a minority against other initiation steps for all the exposure conditions under study.

(iii) In the same way, hydroperoxides accumulate over time, but their concentration reaches a much lower final value, typically ranged between 0.05 and $0.10 \mathrm{~mol} \mathrm{~L}^{-1}$ whatever the exposure conditions. This value is much lower than the steady concentration of hydroperoxides found for pure thermal oxidation at the same temperature. Indeed, their steady concentration is a decreasing function of temperature [30,47]: in air, it is $0.6,0.5$ and $0.4 \mathrm{~mol} \mathrm{~L}^{-1}$ at 80,60 and $45^{\circ} \mathrm{C}$ respectively. This result suggests that hydroperoxides photolysis would be a source of radicals as important as hydroperoxides thermolysis for all the exposure conditions under study. Thereby, it justifies the MCLMS (Fig. 1) proposed for describing the photothermal oxidation of polypropylene.

(iv) In contrast, $M_{\mathrm{n}}$ and $M_{\mathrm{w}}$ decrease continuously over time, with a sharpest drop at the end of the induction period. Contrarily to pure thermal oxidation, where a shoulder was observed in the molecular mass distribution at the end of the induction period, especially at $60^{\circ} \mathrm{C}[30]$, there is no sign of crosslinking or branching process. This result confirms that the relative predominance of chain scission over crosslinking is accentuated for all the exposure conditions under study by the existence of the additional initiation step of hydroperoxides photolysis.

A first interesting characteristic of the photothermal oxidation is the concentration ratio between chain scissions (on main polymer chain) and carbonyl products: $S /[P=0]$, i.e. $\gamma_{s} / \gamma_{1}$. It is noteworthy that for sufficient conversion degrees of oxidation (i.e. typically for $[\mathrm{P}=\mathrm{O}]>0.01 \mathrm{~mol} \mathrm{~L}^{-1}$, a critical value above which the sensitivity of spectrophotometry techniques does not generate high experimental scattering), all datasets overlap irrespectively to exposure conditions, including temperature, UV-light intensity and sources (see Fig. 7). It was found that: $\gamma_{s} / \gamma_{1}=0.97 \pm 0.05$. When neglecting crosslinking, this ratio decreases to $0.70 \pm 0.04$, a value to be compared with the value of 0.75 found in the case of pure thermal oxidation for the same reference iPP, but also for a compilation of literature data (see Table 4 in reference [30]).

A second interesting characteristic of the photothermal oxidation is the concentration ratio between chain scissions (on main polymer chain) and crosslinks: S/B (Fig. 8). It is found that $\mathrm{S} / \mathrm{B}=10.6 \pm 1.0$, a value to be compared to the value of $9.6 \pm 2.7$ found in the case of pure thermal oxidation for the same reference iPP [30]. This result tends to temper the role played by the additional chain scissions on the embrittlement process of iPP under UV-light exposure, especially at high irradiances.

\subsection{Data scattering}

The quality of experimental data can also be criticized. First of all, the different datasets obtained by carbonyls monitoring enable 

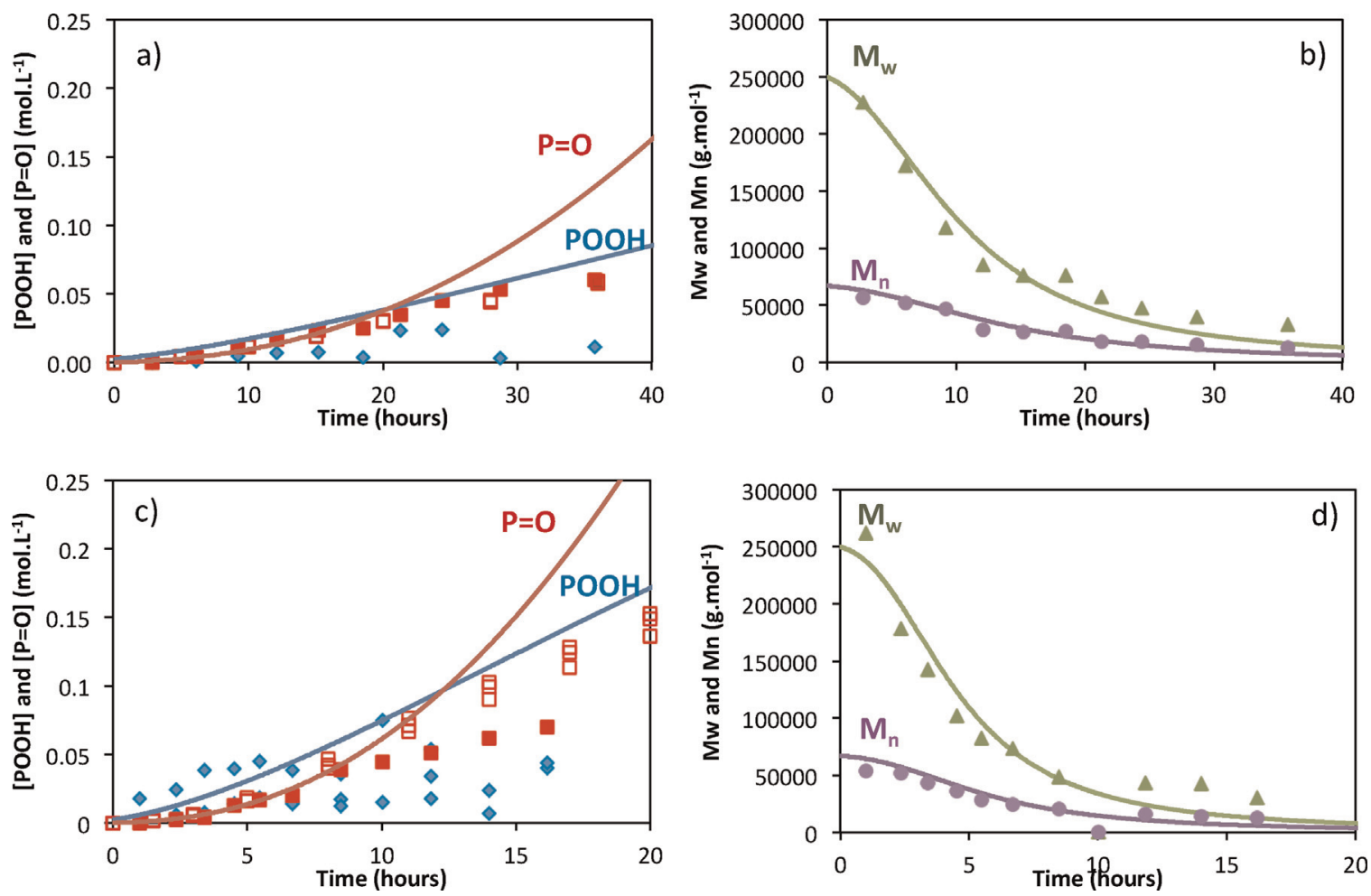

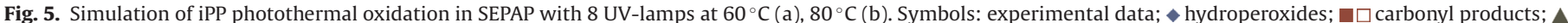
weight and number average molecular masses. Solid lines: kinetic modeling.

to apprehend the aging reproducibility, i.e. the suitable control of both material variability and exposure conditions. Both datasets are usually overlapped, except for certain samples, typically for concentrations above $0.07 \mathrm{~mol} \mathrm{~L}^{-1}$ (i.e. for moderate conversion degrees of oxidation). Therefore, oxidation rate can suffer slight deviations, presumably owing to the diffusion control of oxidation (DLO) for the thickest samples exposed in the harshest conditions.

Hydroperoxides titrations were also reproducible and consistent over exposure time, but showed a higher experimental scattering. This results can potentially come from: (i) the material variability, (ii) the poor accuracy of the titration method or procedure, given the low values of hydroperoxides concentration to be determined, (iii) a waiting time not long enough to allow the titration reagent to diffuse until the core of the thickest samples, and (iv) a partial titration of all the hydroperoxide type species responsible for the initiation of photothermal oxidation. Among other types of hydroperoxides, one could mention peracids, whose fast decomposition could govern the oxidation rate, but not the length of the induction period $[48,49]$.

\section{Kinetic modeling and discussion}

\subsection{Optimization procedure - numerical simulations and determination of unknown parameters}

Many parameters are involved in the kinetic model for photothermal oxidation of iPP. Those appearing only in the CLMS (i.e. rate constants and yields of reactions $1 \mathrm{u}, 1 \mathrm{~b}$, and 2-6d) were determined in a previous study from thermal aging experiments in
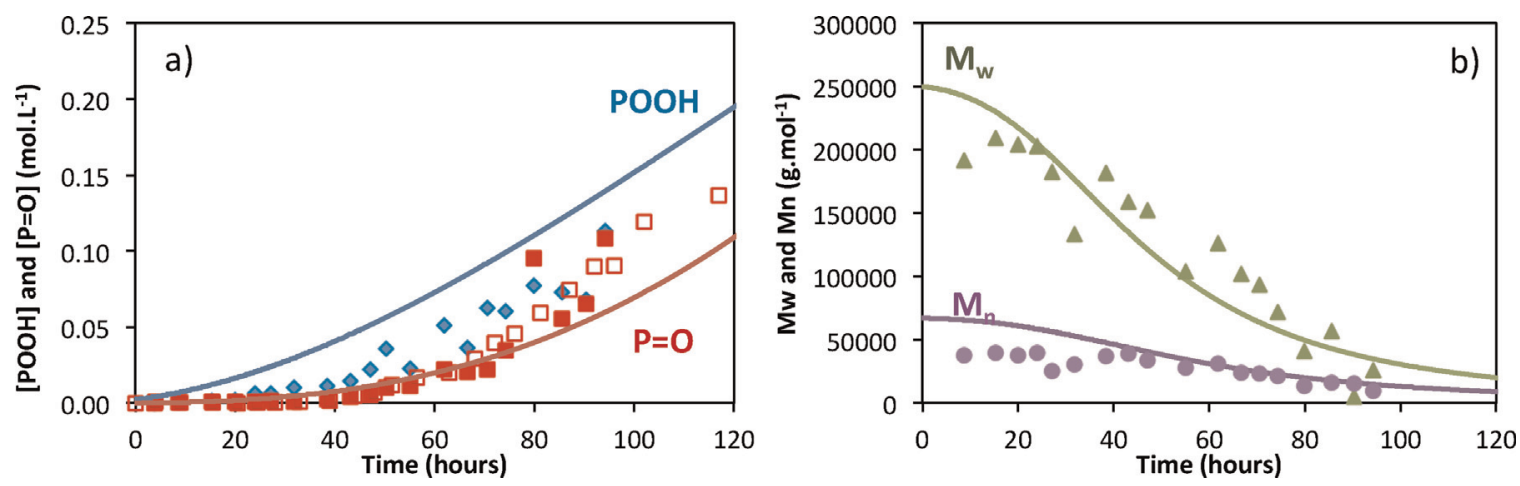

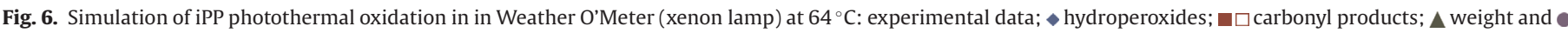
number average molecular masses. Solid lines: kinetic modeling. 


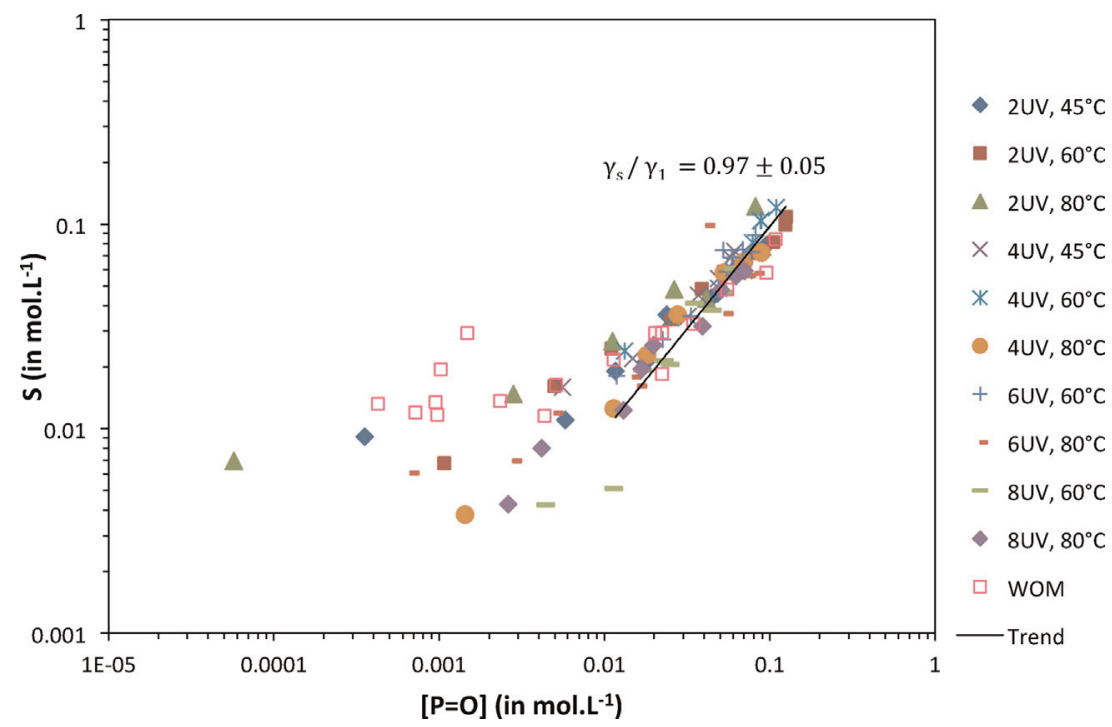

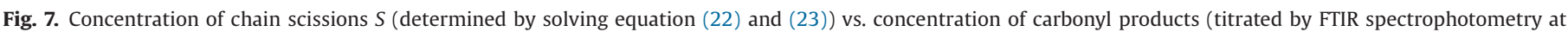
$1713 \mathrm{~cm}^{-1}$ ) for iPP exposed in SEPAP (with 2, 4, 6 or $8 \mathrm{UV}$-lamps) at 45,60 and $80^{\circ} \mathrm{C}$, and in WOM (Xenon lamp) at $64{ }^{\circ} \mathrm{C}$.

a large range of temperatures $\left(60-140^{\circ} \mathrm{C}\right)$ and oxygen partial pressures (0.02-5 MPa) [30]. Their values are reminded in Table 2.

It is important to precise that middle-chain $\left(K_{\mathrm{A}}\right)$ and end-chain ketones $\left(K_{\mathrm{B}}\right)$ have not been differentiated from each other in the previous study [30]. Indeed, the concentration changes in carbonyl products were modeled by using an apparent yield $\gamma_{1}$ stemming from FTIR monitoring at $1713 \mathrm{~cm}^{-1}$. Obviously, the value of $\gamma_{1}$ should be kept unchanged at 0.5 in the present study in order to ensure a perfect continuity with the thermal oxidation model. For the same reason, the yield in chain scissions (on main polymer chain) $\gamma_{S}$ should be also kept unchanged at 0.5 . In a first approach, their values can be deduced from the ratio: $\gamma_{S} / \gamma_{1}=0.97 \pm 0.06$ determined experimentally (see Fig. 7). Taking $\gamma_{1}=0.5$, it comes effectively: $\gamma_{s}=0.48 \pm 0.03$, which is very close to 0.5 .

If this first value of $\gamma_{s}$ allowed simulating satisfactorily all the kinetic curves of hydroperoxides concentration and average molecular masses shown on Figs. 2-6, in contrast, the value of $\gamma_{1}$ underestimated largely the concentrations of carbonyl products (assumed to be exclusively composed of ketones). A possible explanation could be that the distribution of carbonyl products is different from pure thermal to photothermal oxidation, due to a partial photolysis of ketones (by Norrish 1 and 2 reactions). In such a case, the value of molar extinction coefficient $\varepsilon^{\mathrm{P}=\mathrm{O}}$ conventionally (but arbitrarily) fixed at $300 \mathrm{~mol} \mathrm{~L}^{-1} \mathrm{~cm}^{-1}$ at $1713 \mathrm{~cm}^{-1}$ in pure thermal oxidation, should be reconsidered in photothermal oxidation. Indeed, it should not be forgotten that, if the molar extinction coefficients of ketones is relatively low (typically between 200 and $400 \mathrm{~mol} \mathrm{~L}^{-1} \mathrm{~cm}^{-1}$ ), whereas those of carboxylic acids $\left(650-850 \mathrm{~mol} \mathrm{~L}^{-1} \mathrm{~cm}^{-1}\right)$ and esters are much higher (450$\left.600 \mathrm{~mol} \mathrm{~L}^{-1} \mathrm{~cm}^{-1}\right)$.

For this reason, in a second approach, the values of $\gamma_{1}$ was fixed in agreement with the distribution of carbonyl products determined in the literature in photothermal oxidation [30,50-53], in particular from the results of Carlsson and Wiles [1-3]. First of all, $\gamma_{1}$ was increased up to 0.6 , since it was reported that more than half the alkoxy radicals undergo $\beta$ scission $[1,2]$. Then, $\gamma_{1}^{\prime}$ and $\gamma_{1}^{\prime \prime}$

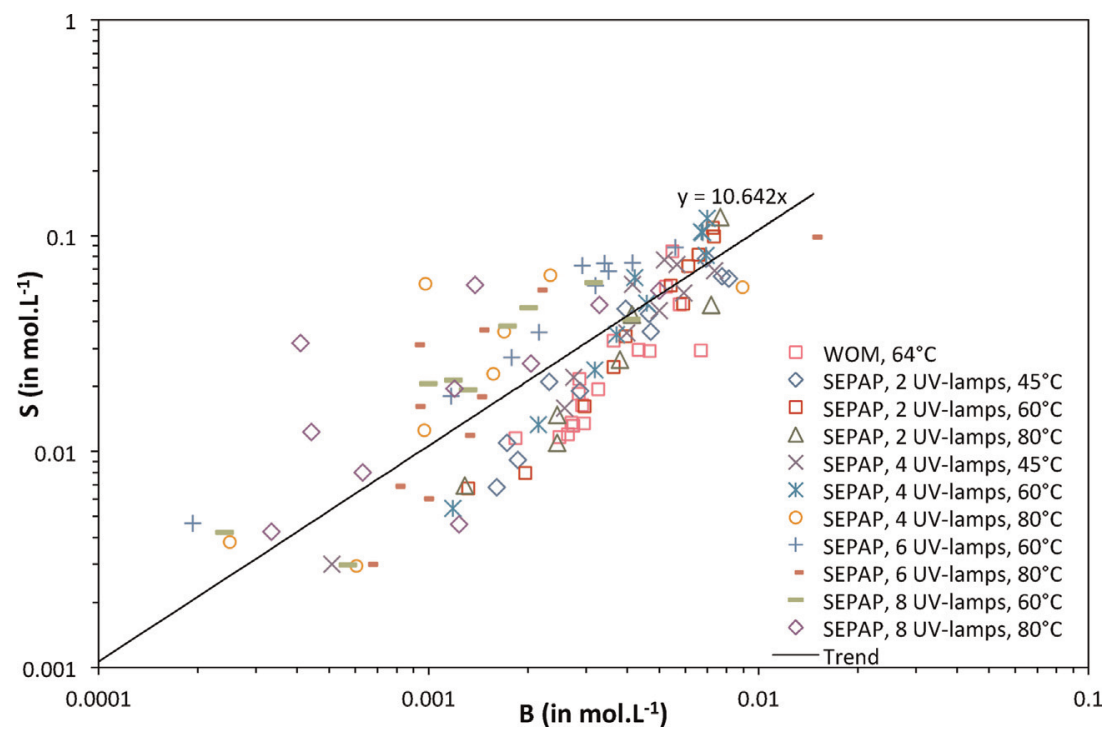

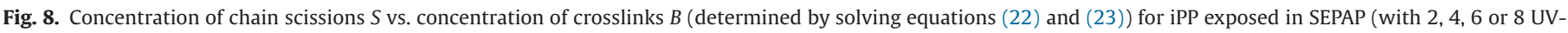
lamps) at 45,60 and $80^{\circ} \mathrm{C}$, and in WOM (xenon lamp) at $64^{\circ} \mathrm{C}$. 
Table 2

Parameters used for kinetic modeling of iPP thermal oxidation [30] in the photothermal problem.

\begin{tabular}{llll}
\hline Parameters & Units & $\mathrm{P}^{0}$ & $\mathrm{Ea}\left(\mathrm{kJ} \mathrm{mol}^{-1}\right)$ \\
\hline$[\mathrm{POOH}]_{0}$ & $\mathrm{~mol} \mathrm{~L}^{-1}$ & $4 \times 10^{-3}$ & - \\
$\mathrm{S}_{\mathrm{O}_{2}}^{\mathrm{am}}$ & $\mathrm{mol} \mathrm{L}^{-1} \mathrm{~Pa}^{-1}$ & $2.5 \times 10^{-6}$ & 6.7 \\
$\mathrm{D}_{\mathrm{O}_{2}}$ & $\mathrm{~m}^{2} \mathrm{~s}^{-1}$ & $8.6 \times 10^{-6}$ & 36.4 \\
$\mathrm{Pe}_{\mathrm{O}_{2}}$ & $\mathrm{~cm}^{3} \mathrm{~cm} \mathrm{~cm}^{-2} \mathrm{~Pa}^{-1} \mathrm{~s}^{-1}$ & $2.9 \times 10^{-6}$ & 43.0 \\
$\mathrm{k}_{1 \mathrm{u}}$ & $\mathrm{s}^{-1}$ & $2.9 \times 10^{13}$ & 140.7 \\
$\mathrm{k}_{1 \mathrm{~b}}$ & $\mathrm{~L} \mathrm{~mol}^{-1} \mathrm{~s}^{-1}$ & $9.2 \times 10^{8}$ & 95.0 \\
$\mathrm{k}_{2}$ & $\mathrm{~L} \mathrm{~mol}^{-1} \mathrm{~s}^{-1}$ & $3.0 \times 10^{9}$ & 10.0 \\
$\mathrm{k}_{3}$ & $\mathrm{~L} \mathrm{~mol}^{-1} \mathrm{~s}^{-1}$ & $5.1 \times 10^{7}$ & 62.2 \\
$\mathrm{k}_{4}$ & $\mathrm{~L} \mathrm{~mol}^{-1} \mathrm{~s}^{-1}$ & $1.0 \times 10^{12}$ & 0 \\
$\mathrm{k}_{5}$ & $\mathrm{~L} \mathrm{~mol}^{-1} \mathrm{~s}^{-1}$ & $4.5 \times 10^{10}$ & 0 \\
$\mathrm{k}_{6 \mathrm{a}}$ & $\mathrm{L} \mathrm{mol}$ & \\
$\mathrm{k}_{6 \mathrm{~b}}$ & $\mathrm{~s}^{-1}$ & $2.0 \times 10^{17}$ & 90.0 \\
$\mathrm{k}_{6 \mathrm{~d}}$ & $\mathrm{~s}^{-1}$ & $6.7 \times 10^{6}$ & 5.0 \\
$\gamma_{1}$ & $\%$ & $1.4 \times 10^{12}$ & 41.0 \\
$\gamma_{1}^{\prime}$ & $\%$ & 60 & - \\
$\gamma_{1}^{\prime \prime}$ & $\%$ & 27 & - \\
$\gamma_{4}$ & $\%$ & 33 & - \\
$\gamma_{5}$ & $\%$ & 0 & - \\
$\gamma_{\mathrm{s}}$ & $\%$ & 0 & - \\
\hline
\end{tabular}

were respectively fixed at 0.27 and 0.33 knowing the concentration ratio of 0.82 was determined between ketones $A$ and $B$ [1,2].

Once known the parameters of the CLMS, the objective was to determine the additional effects of UV-light and their corresponding parameters. Since the rate constants $k_{\mathrm{i}}$ of the photo-induced reactions can be written as follows: $k_{\mathrm{i}}=\Phi_{\mathrm{i}} \times J_{\mathrm{i}}$, the spectral overlap integrals $J_{\mathrm{i}}$ were calculated for each chromophore $\mathrm{i}$ under consideration (according to the calculation procedure given in Section 3.2.2), prior to determine the quantum yields $\Phi_{\mathrm{i}}$. There was no additional adjustable parameter.

The values of $J_{\mathrm{i}}$ are reported in Table 3.

Then, the quantum yields of peroxide type species (i.e. $\phi_{\mathrm{POOH}}$ and $\phi_{\mathrm{POOP}}$ ) and ketones photolysis (i.e. $\phi_{\mathrm{N} 1 \mathrm{~A}}, \phi_{\mathrm{N} 1 \mathrm{~B}}, \phi_{\mathrm{N} 2 \mathrm{~A}}, \phi_{\mathrm{N} 2 \mathrm{~B}}$ ), were determined by adjusting the concentration changes in hydroperoxides, ketones/carbonyls and double bonds, but also the changes in molecular masses. The value of $\phi_{\mathrm{POOH}}$ was fixed first, since hydroperoxides are considered as the primary oxidation products $[3,55,56]$.

\subsection{Relative predominance of initiating species}

\subsubsection{Hydroperoxides vs. ketones contribution}

Surprisingly, small variations in $\phi_{\mathrm{POOH}}$ around its optimal value have almost no effect on the kinetic curves of hydroperoxides. This is presumably due to the presence of several imbricated closed-loops in the MCLMS, which makes the photothermal oxidation behavior hardly predicable. $\phi_{\mathrm{POOH}}$ was thus adjusted basing mainly on the changes in carbonyl products and molecular masses. Since ketones $K_{\mathrm{A}}$ and $K_{\mathrm{B}}$ have been differentiated in the MCLMS, it was then possible to study the impact of their respective quantum yields on the overall photothermal oxidation kinetics. As observed experimentally by Carlsson and Wiles [2], Norrish 1 and 2 reactions would not have the same degree of sensitivity on ketones $K_{\mathrm{A}}$ and $K_{\mathrm{B}}$.
The absence of Norrish 2 reaction on ketones A is understandable because it requires a peculiar chain conformation for having a six-membered rearrangement. Indeed, this reaction would be constrained in middle-chain due to bond tension, but favored at chain extremities where methyl substituents could promote more mobility. This assumption is in perfect agreement with the literature ([2,15,34,44,51,57-59]) which generally reports values of $\phi_{\mathrm{N} 2}$ varying in the following order: end-chain $>$ middle-chain $>$ side-chain, except for ketones formed in PE [15] (see Fig. A2 in Supporting information). As an example, $\phi_{\mathrm{N} 2}$ is twice higher for end-chain $\left(\phi_{\mathrm{N} 2}=0.22\right)$ than for middle-chain ketones $\left(\phi_{\mathrm{N} 2}=0.11\right)$ in 8-pentadecanone [60]. This result would be independent of temperature or physical state (film, solution, etc.) because of the relatively high lifetime of the transient triplet state.

The lower value of $\phi_{\mathrm{N} 1}$ for ketones $K_{\mathrm{B}}$ than for ketones $K_{\mathrm{A}}$ is also in good agreement with the values reported in the literature $([2,15,58-62])$ for end-chain and middle-chain ketones (see Fig. A1 in Supporting information), but more difficult to understand particularly when considering that aldehydes also undergo Norrish 1 reaction. The selective quenching of end-chain ketones can be envisaged, but it would also prevent Norrish 2 reaction. These quantum yields were, thus assumed to be independent from each other for the different kinds of ketones.

From this standpoint, a parametric study involving different combinations of $\phi_{\mathrm{POOH}}$ on one side, and $\phi_{\mathrm{N} 1 \mathrm{~A}}, \phi_{\mathrm{N} 1 \mathrm{~B}}, \phi_{\mathrm{N} 2 \mathrm{~A}}$ and $\phi_{\mathrm{N} 2 \mathrm{~B}}$ on the other side, has been performed with values ranging from 1 to 10 for $\mathrm{POOH}$ photolysis and 0 to 0.03 for Norrish type reactions. The parametric study has been led preferentially in exposure conditions where photochemical initiation is predominant over thermal initiation, in order to enhance the sensitivity of quantum yields. This optimization procedure was thus performed on the SEPAP results obtained with 4 UV-lamps at $45^{\circ} \mathrm{C}$.

Results are depicted in Fig. 9, for $\phi_{\mathrm{N} 1 \mathrm{~B}}$ and $\phi_{\mathrm{N} 2 \mathrm{~A}}$ set at zero. Hydroperoxides concentration was highly sensitive to Norrish 1 reaction, unlike carbonyls concentration. From the changes in hydroperoxides concentration, it can be concluded that $\phi_{\mathrm{N} 1}$ must be kept lower than 0.01 . Similarly, all the ethylenic unsaturations would come from termination reactions (in particular, disproportionation) and therefore, $\phi_{\mathrm{N} 2}$ would be also lower than 0.01. It also appears that the changes in molecular masses are weakly sensitive to ketones photolysis with such low values of quantum yields. All these results are consistent with the compilation of literature data (see Figs. A1 and 2 in Supporting information).

Before concluding that the contribution of Norrish type reactions can be neglected compared with hydroperoxides photolysis, it remained to check that this result does not depend on the way whose kinetic model is initialized, i.e. on the choice of the initial concentrations in hydroperoxides $[\mathrm{POOH}]_{0}$ and ketones $\left[K_{\mathrm{A}}\right]_{0}$ and $\left[K_{\mathrm{B}}\right]_{\mathrm{O}}$. Indeed, in the previous kinetic submodel for pure thermal oxidation [29], the initial amount of structural defects responsible for the extrinsic initiation, that only predominates in the early stages of oxidation, was successfully accounted by an (kinetically equivalent) initial concentration in hydroperoxides $[\mathrm{POOH}]_{0}$. In contrast, in the kinetic models of pure photooxidation developed by Sommersal and Guillet [15] and Geuskens et al. [56], these defects

Table 3

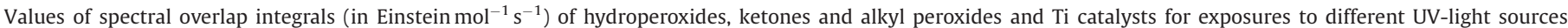
(calculated from absorption spectra given in references [1,54],[2] and [1] respectively).

\begin{tabular}{|c|c|c|c|c|}
\hline Light source & $J_{\mathrm{POOH}}$ & $J_{\mathrm{PO}}$ & $J_{\mathrm{POOP}}$ & $J_{\text {Ticatalysts }}$ \\
\hline SEPAP $12-24,2$ arc mercury lamps & $4.92 \mathrm{E}-06$ & 7.31E-05 & $8.40 \mathrm{E}-06$ & $5.23 \mathrm{E}-03$ \\
\hline SEPAP $12-24,4$ arc mercury lamps & $1.07 \mathrm{E}-05$ & $1.46 \mathrm{E}-04$ & $1.68 \mathrm{E}-05$ & $1.05 \mathrm{E}-02$ \\
\hline SEPAP 50-24, 6 arc mercury lamps & $2.54 \mathrm{E}-05$ & 3.77E-04 & 4.33E-05 & 2.69E-02 \\
\hline SEPAP 50-24, 8 arc mercury lamps & $5.53 \mathrm{E}-05$ & 7.53E-04 & 8.67E-05 & 5.39E-02 \\
\hline WeatherO'Meter, xenon lamp & $1.45 \mathrm{E}-06$ & $2.25 \mathrm{E}-05$ & 4.19E-06 & 1.49E-03 \\
\hline Philips TLK 05 lamp fluorescent lamp [9] & $1.45 \mathrm{E}-07$ & $2.31 \mathrm{E}-06$ & $4.71 \mathrm{E}-07$ & $1.45 \mathrm{E}-04$ \\
\hline
\end{tabular}



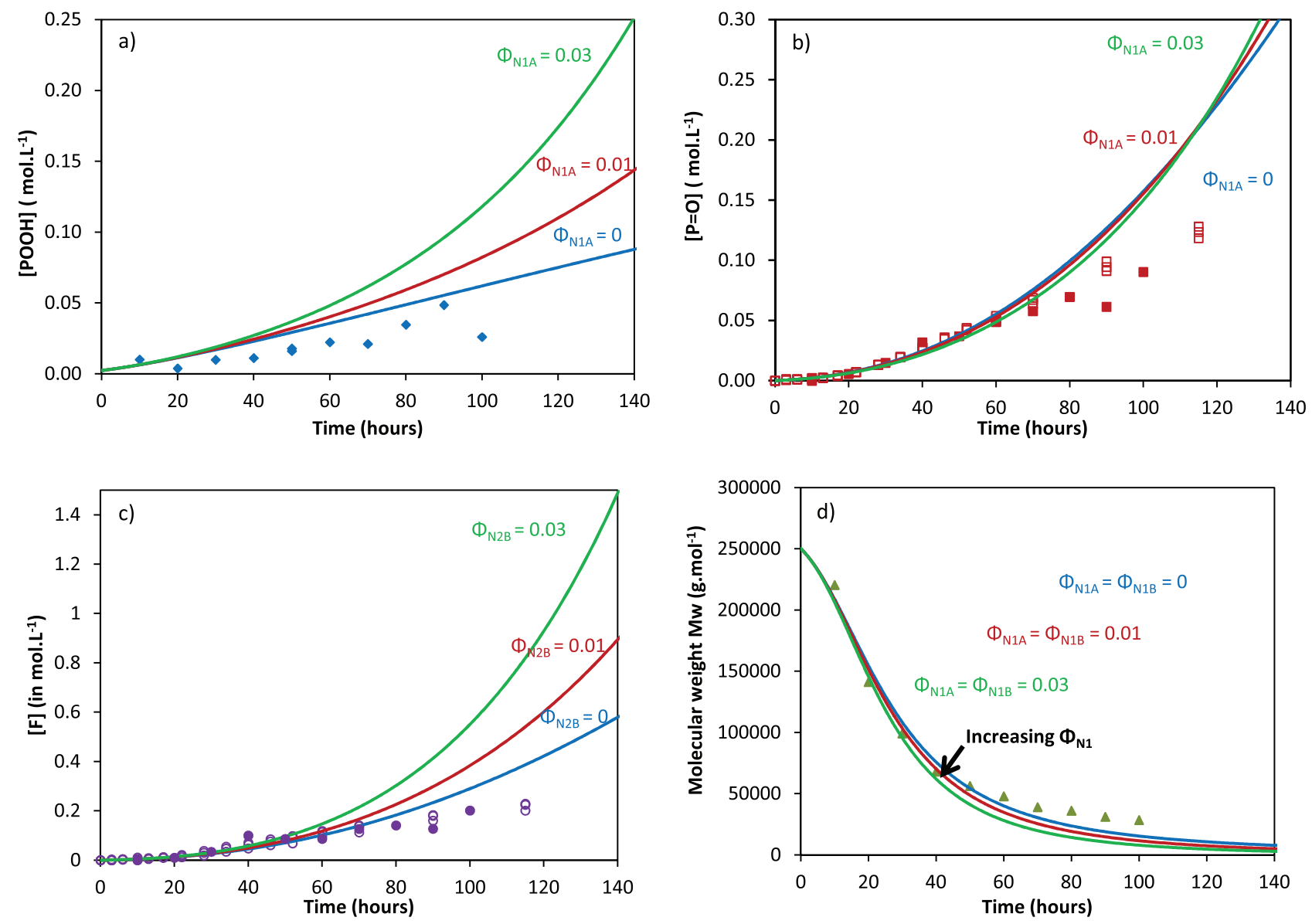

Fig. 9. Optimization of quantum yields for Norrish 1 and 2 reactions. Symbols: experimental data. Solid lines: kinetic modeling.

were replaced by an initial concentration in ketones. In the present case of photothermal oxidation, both types of initiating species have to be considered. Given the large number of parameters involved in the kinetic model of photothermal oxidation, the problem of determining the most relevant chemical species appears as badly conditioned. In order to ensure the continuity with the submodel of pure thermal oxidation (and thus, the relevancy of the kinetic modeling approach), the following strategy has been adopted. The initial concentration in hydroperoxides was kept unchanged at $[\mathrm{POOH}]_{0}=4 \times 10^{-3} \mathrm{~mol} \mathrm{~L}^{-1}$ for the same reference iPP. Thus, the initial concentration in ketones was determined so as to account for the potential surplus of the extrinsic initiation, induced by the photosensitive species. In our case, it was checked that values ranged from 0 to $10^{-3} \mathrm{~mol} \mathrm{~L}^{-1}$ for this last concentration has no influence on simulations, presumably because the contribution of Norrish type reactions to oxidation is negligible compared with hydroperoxides photolysis.

\subsubsection{Contribution of the photolysis of peroxide bridges (alkyl peroxides)}

In a previous paper [21], it was shown that alkyl-peroxides are more photosensitive than hydroperoxides while their $\mathrm{O}-\mathrm{O}$ bond is almost as cleavable. Then, their photolysis must also occur. In a first approach, the value of $\phi_{\mathrm{POOP}}$ was set between 1 and the value previously determined for $\phi_{\mathrm{POOH}}$ as upper boundary. As expected, the introduction of the alkyl-peroxides photolysis induces a slight decrease in the quantum yield of hydroperoxides photolysis $\phi_{\mathrm{POOH}}$, but has no influence on the quantum yields of Norrish type reactions.

From all these results, it can be concluded that: (i) The contribution of Norrish type reactions to iPP photothermal oxidation is almost negligible. The findings with 4 UV-lamps at $45^{\circ} \mathrm{C}$ can be extended to the whole photothermal aging conditions under investigation, since, primary processes are independent of temperature as long as the quantum theory is valid (i.e. for moderate UV-light intensities for which termolecular reactions and multiphotonic excitations are negligible).

(ii) The consideration of alkyl-peroxides photolysis enables to slightly decrease the value of $\phi_{\mathrm{POOH}}$, but it is not indispensable for simulating the experimental data.

\subsection{Validity of the kinetic model}

A single set of quantum yields was determined using the kinetic model of photothermal oxidation as an inverse approach for all the exposure conditions under study. However, it is relevant to be precise that these latter conditions cover a domain where photochemical initiation largely predominates (above 90\%) over thermal initiation, even in WOM device. This is the reason why the validity of the kinetic model was also tested in intermediary exposure conditions where both thermolysis and photolysis contribute to initiation with a similar order of magnitude (as evidenced in previous work [21]). As an example, the simulation of the kinetic curves of carbonyl products reported by Audouin et al. [55] for iPP exposed to fluorescent lamp between 40 and $70{ }^{\circ} \mathrm{C}$ is presented in Fig. 10.

It is found that $\phi_{\mathrm{POOH}}$ ranges between 1.5 and 5.5 in the whole domain of exposure conditions under investigation. The different values are depicted in Fig. 11 in function of the spectral overlap 


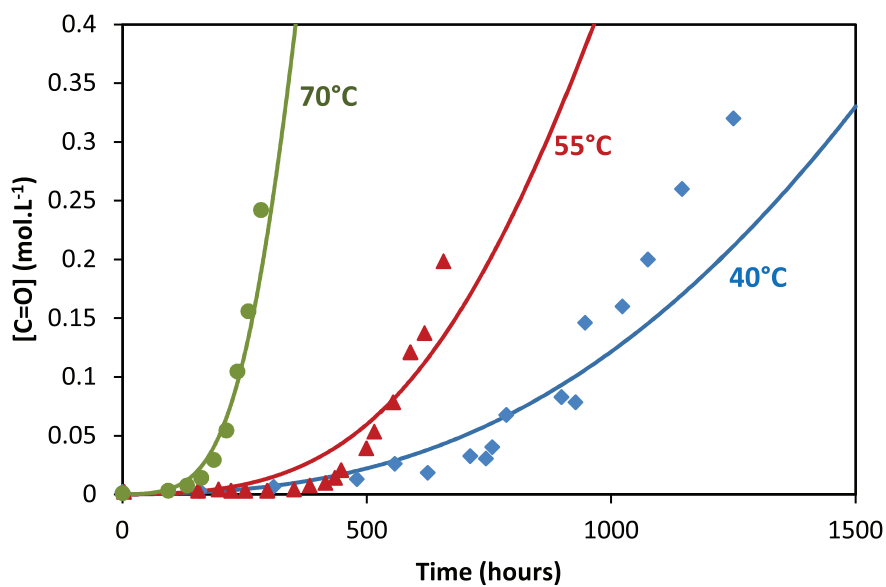

Fig. 10. Simulation of carbonyl products build-up in iPP exposed to Philips TLK 05 fluorescent lamp (spectral distribution with maximum at $365 \mathrm{~nm}$ ) at 40, 55 and $70^{\circ} \mathrm{C}$. Symbols: experimental data [55]. Solid lines: kinetic modeling.

integral as abscissa. In most of cases, $\phi_{\mathrm{POOH}}$ belongs to the variation domain of $4 \pm 1$ (colored in red), in agreement with the experimental findings of Carlsson and Wiles [1] and in general agreement with the literature (see Table A1 in Supporting information). This is an important result in favor of our kinetic modeling approach. Indeed, it confirms that the photo-thermal oxidation of iPP can be satisfactorily described by extending the common CLMS, in particular by introducing additional initiation steps corresponding to the photolysis of peroxide type species.

It is also noteworthy that this value of $\phi_{\mathrm{POOH}}$ is twice lower than the value found by using the analytical kinetic model $\left(\phi_{\mathrm{POOH}}=8\right)$ in a previous publication [21]. Since ketones and peroxide bridges photolysis have been found to have negligible contribution to the photothermal oxidation kinetics, most of the modeling improvement comes from a better description of the coupling between temperature and UV-light effects in the numerical kinetic model. This is also noteworthy that this value is in perfect agreement with the experimental findings of Carlsson and Wiles [1] whose photochemical (e.g. molar absorptivity) and mechanistic characteristics (e.g. concentration ratio of oxidation products) have been reused in this study. Despite this improvement, values of $\phi_{\mathrm{PоOH}}$ are still too high, since they should not theoretically exceed unity in the case of primary processes such as bond dissociation, thus

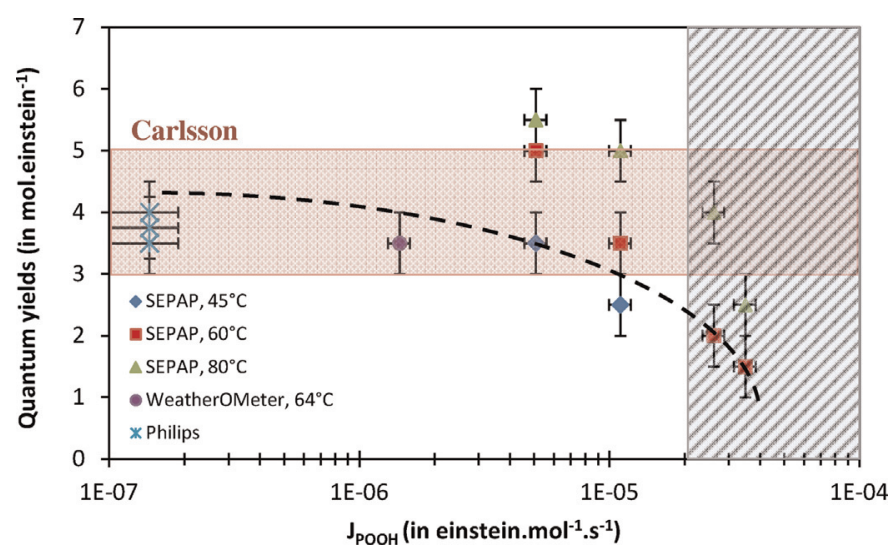

Fig. 11. Quantum yields of hydroperoxides photolysis determined by inverse resolution method. The domain colored in pink applies to the value proposed by Carlsson and Wiles [1]. The hachured domain applies to the domain where the kinetic model is presumably not valid anymore. (colors are available in the online version) questioning on their physical meaning. Different explanations were discussed by Carlsson and Wiles [1]:

(i) The probable underestimation of the corresponding molar extinction coefficient, which was estimated from model compounds. These authors particularly highlighted the difficulty to measure this quantity in hydrocarbon polymers, but also the lack of knowledge on the impact of the polymer chain length and polarity of reactive medium.

(ii) The existence of energy transfers, i.e. the photosensitization of the hydroperoxides decomposition by ketones or catalyst residues.

Both options could also explain the trend of $\phi_{\mathrm{POOH}}$ to decrease when increasing the UV-light intensity (i.e. $\mathrm{J}_{\mathrm{POOH}}$ ), as materialized by the dashed line in Fig. 11. Different other explanations can be envisaged:

(i) The experimental data would not be enough accurate or reliable for the highest irradiances (ultra-acceleration) despite the careful control of exposure conditions. Indeed, the temperature regulation turned out to be awkward, in particular because of the fast oxidation kinetics. However, this possibility is considered as unlikely, since the decreasing trend of $\phi_{\mathrm{POOH}}$ is too obvious to be coincidental.

(ii) The occurrence of multiphotonic excitations (electronic transitions up to orbitals higher than the LUMO) which would finally reduce the average efficiency of quanta. This kind of excitation would predominate above a critical value of light intensity, which could potentially set an intrinsic validity frontier for the kinetic model.

(iii) Other mechanistic considerations would be necessary in order to properly describe the experimental results, particularly in terms of nature and molecularity of chemical reactions.

Moreover, one can observe that the kinetic model hardly accounts for the curvatures of the kinetic curves of carbonyl products at the end of the induction period. This auto-accelerated character of photothermal oxidation is more particularly highlighted at low (see, for instance, results of Girois [55] at 40 and $55^{\circ} \mathrm{C}$ in Fig. 10) and high irradiances (Figs. 5 and 6). It is generally attributed to a predominant initiation by the bimolecular decomposition of hydroperoxies. In photooxidation, this bimolecular decomposition is a termolecular process (two molecules with one quantum), and thus, is usually thought to have a low probability of occurrence except in the case of high irradiances (where quanta are in large excess compared with molecular species), or in the case of formation of relatively stable associations between two molecular species such as excimers/ exciplexes, or charge transfer complex (CT). Such molecular edifices, stabilized by hydrogen bonding as reversible interactions, would include in the present case:

(i) Energy transfers from the highly photosensitive ketones to very cleavable hydroperoxides, since associated in complexes. This would be an argument in favor of the mechanism proposed by Geuskens and Kabamba [63,64];

(ii) Photosensitization of hydroperoxides decomposition by catalyst residues;

(iii) Bimolecular decomposition of hydroperoxides, associated in pairs or constituting longer sequences, was shown to predominate in the case of pure thermal oxidation at low temperature. However, the yield in water formation would suggests an unimolecular instead of a bimolecular hydroperoxides decomposition by 


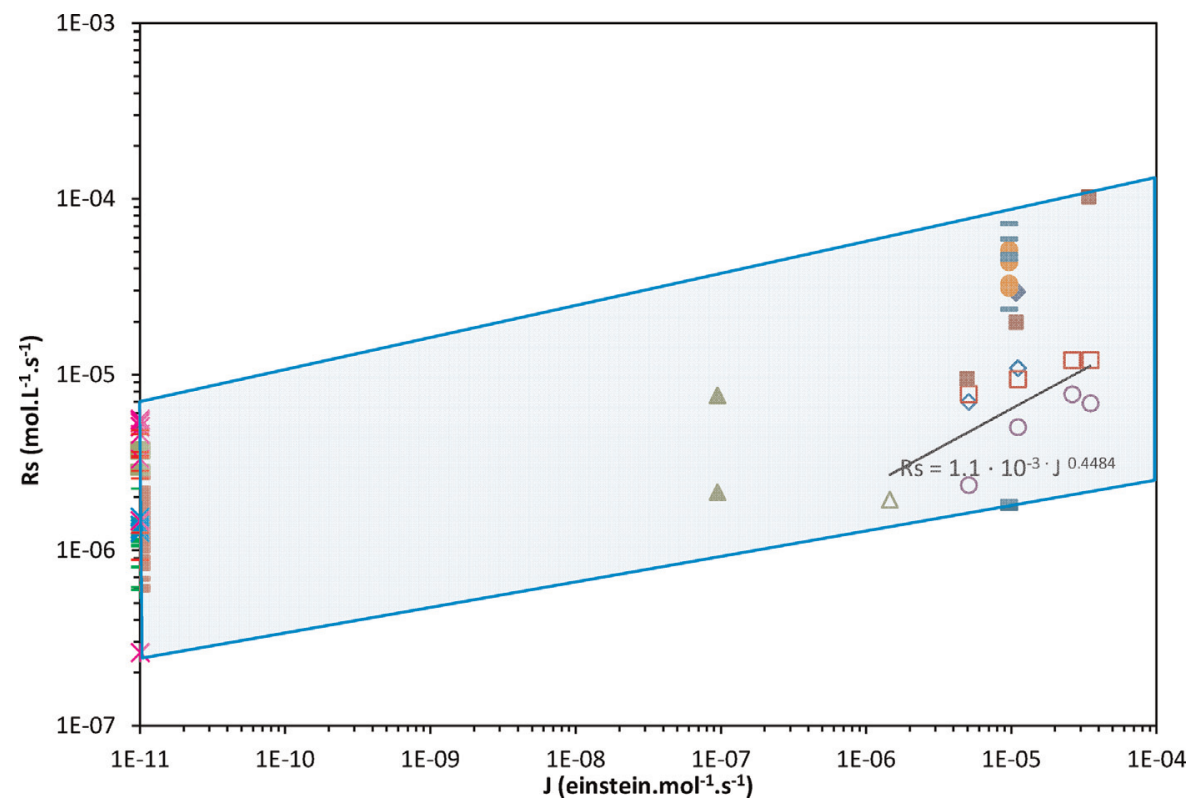

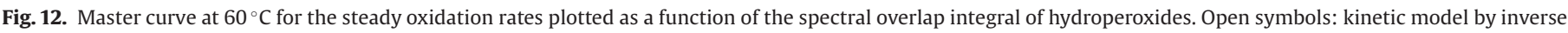

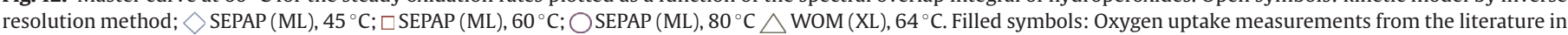

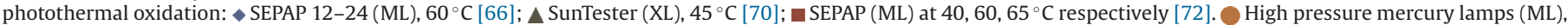

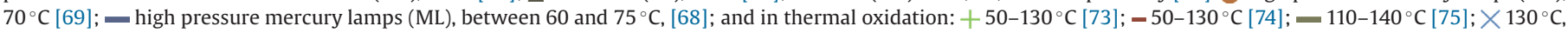
[76]; $\nVdash 80$ and $130^{\circ} \mathrm{C}[77,78] ;+120-140{ }^{\circ} \mathrm{C}$ [79-82]. Arrows indicate the variation range of steady oxidation rate in the case of pure thermal aging.

photolysis (this argument was already used by Carlsson to dismiss the assumption of radicals induced hydroperoxides decomposition) [1].

Although, their complete kinetic treatment remains awkward, our first implementations of these reactions into the kinetic model enable to dismiss the former option.

Furthermore, the kinetic model enables to calculate the maximal rate of oxygen consumption, i.e. the steady oxidation rate $R_{\mathrm{s}}$. Unlike carbonyl products, oxygen is directly involved in the MCLMS and its concentration does not depend on the choice of apparent yields. The values of $R_{\mathrm{s}}$ were determined by the kinetic model for all photothermal aging conditions under study. Then, they were plotted vs. the spectral overlap integral relative to hydroperoxides $\mathrm{J}_{\mathrm{POOH}}$ in Fig. 12 in logarithm-logarithm coordinates. It can be seen that these values are of the same order of magnitude as those deduced from oxygen uptake measurements in the literature [65-70].

A mean-square optimization procedure was applied to determine the activation energy of photothermal oxidation: $71 \mathrm{~kJ} \mathrm{~mol}^{-1}$. This value is slightly lower than the activation energy found for pure thermal oxidation in a previous study: $91 \mathrm{~kJ} \mathrm{~mol}^{-1}$ (see literature compilation in reference [30]).

Finally, a trend curve was tentatively determined. It was found that the steady oxidation rate is proportional to spectral overlap integral (i.e. UV-light intensity) at a power close to $1 / 2$, in close agreement with the usual analytical solution determined from the basic auto-oxidation scheme in the literature $[67,69,71]$. It can be thus written:

$R_{\mathrm{S}}=K \times J^{1 / 2} \times \exp \left({ }^{-} \mathrm{Ea} / \mathrm{RT}_{\mathrm{T}}\right)$

These results confirm the validity and good predictive value of the kinetic model.

\section{Conclusion}

A general kinetic model has been proposed in order to describe the oxidative degradation of polypropylene under the combined effects of UV-light and temperature. The approach consists in modeling the chemical changes of the material and then, to deduce the subsequent changes in physico-chemical and mechanical properties at upper scales by using suitable structure/property relationships. The photochemical processes undergone by photosensitive species, namely peroxide type species and ketones photolysis, were added into the CLMS in order to introduce the effect of UV-light. The photolysis kinetics was expressed by using the spectral overlap integral, which accounts for the energy absorbed by chromophores and initiates oxidation. The resulting kinetic model couples chemical reactions with physical phenomena, such as the oxygen diffusion and light attenuation (screen effect) due to sample opacity and formation of photo-sensitive species. It aims to be fully consistent from a physical point of view and valid for polychromatic UV-light sources and thick specimens.

Currently, this model is used as a research tool based on formal kinetics. The consistency of the different photothermal aging scenarios has been tested. The model parameters have been determined by using the model as an inverse resolution method in order to simulate, as well as possible, the concentration changes in hydroperoxides, carbonyls and double bonds, but also the changes in molecular masses. The model validity has been checked from a substantial aging campaign involving tests on thin films $(100 \mu \mathrm{m}$ of average thickness) in two devices equipped with distinct UV-light sources, namely SEPAP and WeatherO'Meter. Thus, it has been possible to investigate:

(i) The competition between multiple initiating species. Norrish 1 and 2 reactions were shown to be negligible compared with hydroperoxides photolysis.

(ii) The occurrence of energy transfers between these different chemical species. Using the formal kinetic approach, it has 
been shown that the experimental data are compatible with the photosensitization of hydroperoxides by metal chelates (catalyst residues), but not by ketones.

(iii) The consistency of assumptions on oxidation mechanisms, photochemistry (independence of quantum yields upon temperature, molecular weight of photosensitive species and UV-light wavelength) and initial concentrations of initiating species.

Finally, the optimization procedure has led to quantum yields of hydroperoxides photolysis which are consistent with the experimental findings of Carlsson and Wiles. In a first approach, it can be considered that the CLMS can be successfully extended to the case of photothermal oxidation, but only in a restricted domain were the quantum theory provides a suitable description of photochemistry, i.e. for UV-light intensities not involving multiphotonic excitations or termolecular processes.

This result suggests the existence of an upper boundary in the validity range of the kinetic model corresponding to a critical UV-light intensity of about $2 \times 10^{-5}$ Einstein $\mathrm{L}^{-1} \mathrm{~s}^{-1}$, i.e. ten times the UV-light intensity of sunlight (zenith, filtered by the atmosphere).

Irrespectively to the photothermal aging conditions, the value of $\phi_{\mathrm{POOH}}$ exceeds the theoretical maximum for primary processes $\left(\phi_{\mathrm{POOH}}>1\right)$, which is presumably ascribed to a misestimation of the molar extinction coefficient of hydroperoxides, or the photosensitization of hydroperoxides by catalyst residues. The decrease in $\Phi_{\mathrm{POOH}}$ with UV-light intensity, as well as some evidences of bimolecular photochemical decomposition of hydroperoxides (termolecular photophysical process), suggest that the kinetic model can still be improved.

The main advantage of the kinetic modeling approach is its upgradability, which can be discussed regarding at the formal kinetic approach. For instance, if some energy transfers occur, it would be necessary to consider how they may be impacted by the introduction of the effects of other chemical compounds such as stabilizers like quenchers.

Clearly, similar models can be established for all types of polyolefins, but it would involve the same kind of difficulty, i.e. the uncertainty on the nature and relative contribution of structural defects to the initiation step of oxidation. Obviously, this kind of kinetic model of photothermal oxidation would be advantageously applied to other polymers for which the chromophores are clearly identified and their photochemical characteristics measurable with accuracy.

\section{Acknowledgements}

The authors gratefully acknowledge the Carnot-Arts Institute for its financial support to acquire an Agilent Technologies PL-GPC 220 high temperature device and the Centre National d'Evaluation de Photoprotection (Clermont-Ferrand, France) for photothermal aging tests and careful control of exposure conditions.

\section{Supplementary data}

Supplementary data associated with this article can be found, in the online version, at http://dx.doi.org/10.1016/j.jphotochem.2014.08.015.

\section{References}

[1] D.J. Carlsson, D.M. Wiles, The photodegradation of polypropylene films. III. Photolysis of polypropylene hydroperoxydes, Macromolecules 2(1969)597-606.

[2] D.J. Carlsson, D.M. Wiles, The photodegradation of polypropylene films. II. Photolysis of ketonic oxidation products, Macromolecules 2 (1969) 587-597.
[3] D.J. Carlsson, D.M. Wiles, The photooxidative degradation of polypropylene. Part I. Photooxidation and photoinitiation processes, J. Macromol. Sci. Polymer Rev. 14 (1976) 65-106.

[4] A.V. Tobolsky, Oxidative degradation of polymeric material, Disc. Faraday Soc. 2 (1947) 384-388.

[5] A.V. Tobolsky, D.J. Metz, R.B. Mesrobian, Low temperature autoxidation of hydrocarbons: the phenomenon of maximum rates, J. Am. Chem. Soc. 72 (1950) 1942-1952.

[6] J.L. Bolland, G. Gee, Kinetic studies in the chemistry of rubber and related materials. II. The kinetics of oxidation of unconjugated olefins, Trans. Faraday Soc. 42 (1946) 236-243.

[7] L. Reich, S.S. Stivala, Kinetics and mechanism of oxidative degradation of polymers, in: McGraw-Hill (Ed.), Lements of Polymer Degradation, 1971, 229-293.

[8] S.S. Stivala, J. Kimura, S.M. Gabbay, Thermal degradation and oxidative processes, in: N.S. Allen (Ed.), Degradation and Stabilization of Polyolefins, Appl. Sci. Publ., London, 1983, pp. 63-185.

[9] A.V. Cunliffe, A. Davis, Photo-oxidation of thick polymer samples part II: the influence of oxygen diffusion on the natural and artificial weathering of polyolefins, Polym. Degrad. Stab. 4 (1982) 17-37.

[10] G.C. Furneaux, K.J. Ledbury, A. Davis, Photo-oxidation of thick polymer samples part I: the variation of photo-oxidation with depth in naturally and artificially weathered low density polyethylene, Polym. Degrad. Stab. 3 (1981) 431-442.

[11] L. Audouin, V. Langlois, J. Verdu, J.C.M. de Bruijn, Role of oxygen diffusion in polymer ageing: kinetic and mechanical aspects, J. Mater. Sci. 29 (1994) 569-583.

[12] K.T. Gillen, J. Wise, R.L. Clough, General solution for the basic autoxidation scheme, Polym. Degrad. Stab. 47 (1995) 149-161.

[13] X. Colin, C. Marais, J. Verdu, A new method for predicting the thermal oxidation of thermoset matrices: application to an amine crosslinked epoxy, Polym. Test. 20 (2001) 795-803.

[14] X. Colin, C. Marais, J. Verdu, Thermal oxidation kinetics for a poly (bismaleimide), J. Appl. Polym. Sci. 82 (2001) 3418-3430.

[15] A.C. Somersall, J.E. Guillet, Computer modeling studies of polymer photooxidation and stabilization, in: Polymer Stabilization and Degradation, American Chemical Society, 1985, pp. 211-234.

[16] L. Audouin, V. Gueguen, A. Tcharkhtchi, J. Verdu, Closed loop mechanistic schemes for hydrocarbon polymer oxidation, J. Polym. Sci., Part A: Polym. Chem. 33 (1995) 921-927.

[17] S. Verdu, J. Verdu, A new kinetic model for polypropylene thermal oxidation at moderate temperatures, Macromolecules 30 (1997) 2262-2267.

[18] L. Achimsky, L. Audouin, J. Verdu, Kinetic study of the thermal oxidation of polypropylene, Polym. Degrad. Stab. 57 (1997) 231-240.

[19] N. Khelidj, X. Colin, L. Audouin, J. Verdu, C. Monchy-Leroy, V. Prunier, Oxidation of polyethylene under irradiation at low temperature and low dose rate. Part I. The case of pure radiochemical initiation, Polym. Degrad. Stab. 91 (2006) 1593-1597.

[20] S. Kiil, Model-based analysis of photoinitiated coating degradation under artificial exposure conditions, J. Coat. Technol. Res. 9 (2012) 375-398.

[21] A. François-Heude, E. Richaud, E. Desnoux, X. Colin, Influence of temperature, UV-light wavelength and intensity on polypropylene photothermal oxidation, Polym. Degrad. Stab. 100 (2014) 10-20.

[22] J.-L. Gardette, C. Sinturel, J. Lemaire, Photooxidation of fire retarded polypropylene, Polym. Degrad. Stab. 64 (1999) 411-417.

[23] D.W. Mayo, F.A. Miller, R.W. Hannah, Infrared Spectra of Polymers: Introduction, John Wiley and Sons Inc., 2004.

[24] F.M. Rugg, J.J. Smith, R.C. Bacon, Infrared spectrophotometric studies on polyethylene. II. Oxidation, J. Polym. Sci. 13 (1954) 535-547.

[25] D.J. Carlsson, R. Brousseau, D.M. Wiles, Reactions of sulfur dioxide with oxidized polyolefins, Polym. Degrad. Stab. 15 (1986) 67-79.

[26] D.J. Carlsson, J. Lacoste, A critical comparison of methods for hydroperoxide measurement in oxidized polyolefins, Polym. Degrad. Stab. 32 (1991) 377-386

[27] J.M. Evans, Gel permeation chromatography: a guide to data interpretation, Polym. Eng. Sci. 13 (1973) 401-408.

[28] W.W. Yau, J.J. Kirkland, D.D. Bly, Modern Size-Exclusion Liquid Chromatography: Practice of Gel Permeation and Gel Filtration Chromatography, second ed. John Wiley and Sons, 1979.

[29] S. Mori, H.G. Barth, Size Exclusion Chromatography, Springer, 1999.

[30] A. François-Heude, E. Richaud, A. Guinault, E. Desnoux, X. Colin, On the impact of oxygen transport properties on the polypropylene thermal oxidation. Part I: effect of oxygen solubility, J. Appl. Polym. Sci. (2014) in press..

[31] A. François-Heude, E. Richaud, A. Guinault, E. Desnoux, X. Colin, On the impact of oxygen transport properties on the polypropylene thermal oxidation. Part II: effect of oxygen diffusivity, Journal of Applied Polymer Science (2014) in press.

[32] J.G. Calvert, J.N.Jr. Pitts, Photochemistry, John Wiley \& Sons, New York, 1996.

[33] B. Rånby, J.F. Rabek, Photodegradation, Photo-oxidation, and Photostabilization of Polymers: Principles and Applications, John Wiley and Sons, 1975.

[34] J.E. Guillet, J. Dhanraj, F.J. Golemba, G.H. Hartley, in: R.F. Gould (Ed.), Fundamental Processes in the Photodegradation of Polymers, in: Stabilization of Polymers and Stabilizer Processes, Advances in Chemistry Series, No. 85, American Chemical Society, Washington, 1968, pp. 272-286 (Chapter 19).

[35] C. Chatgilialoglu, D. Crich, M. Komatsu, I. Ryu, Chemistry of acyl radicals, Chem. Rev. 99 (1999) 1991-2070.

[36] J.E. Guillet, Photochemistry in macromolecular systems, Naturwissenschaften 59 (1972) 503-509. 
[37] J.C. Dalton, N.J. Turro, Photoreactivity of n,pi* excited states of alkyl ketones, Ann. Rev. Phys. Chem. 21 (1970) 499-560.

[38] J.E. Guillet, Fundamental processes in the UV degradation and stabilization of polymers, Pure Appl. Chem. 30 (1972) 135-144.

[39] M. Heskins, J.E. Guillet, Photochemistry of ketone polymers. III. Energy transfer in ethylene-carbon monoxide polymers, Macromolecules 3 (1970) 224-231.

[40] G. Vaghjiani, A.R.J. Ravishankara, Photodissociation of $\mathrm{H}_{2} \mathrm{O}_{2}$ and $\mathrm{CH}_{3} \mathrm{OOH}$ a $248 \mathrm{~nm}$ and $298 \mathrm{~K}$ : quantum yields for $\mathrm{OH}, \mathrm{O}\left({ }^{3} \mathrm{P}\right)$ and $\left.\mathrm{H}^{2} \mathrm{~S}\right)$, J. Chem. Phys. 92 (1990) 996-1003.

[41] T. Gierczak, J.B. Burkholder, S. Bauerle, A.R. Ravishankara, Photochemistry of acetone under tropospheric conditions, Chem. Phys. 231 (1998) 229-244.

[42] L. Zhu, Y. Tang, Y. Chen, T. Cronin, Wavelength-dependent photolysis of C3-C7 aldehydes in the 280-330 nm region, Spectrosc. Lett. 42 (2009) 467-478.

[43] Searle activation spectra: the activation spectrum and its significance to weathering of polymeric materials, Atlas SunSpots, 14, 1984.

[44] Z. Zhenfeng, H. Xingzhou, L. Zubo, Wavelength sensitivity of photooxidation of polypropylene, Polym. Degrad. Stab. 51 (1996) 93-97.

[45] E. Hairer, G. Wanner, E. Hairer, G. Wanner, 2nd rev. ed., Solving Ordinary Differential Equations II: Stiff and Differential-Agebraic Problems, Series in Computational Mathematics, 14, Springer-Verlag, Berlin, 1996.

[46] O. Saito, The Radiation Chemistry of Macromolecules, in: M. Dole (Ed.), Academic Press, New York, 1972.

[47] E. Richaud, F. Farcas, B. Fayolle, L. Audouin, J. Verdu, Hydroperoxide build-up in the thermal oxidation of polypropylene - a kinetic study, Polym. Degrad. Stab. 92 (2007) 118-124.

[48] P. Gijsman, J. Hennekens, J. Vincent, The mechanism of the low-temperature oxidation of polypropylene, Polym. Degrad. Stab. 42 (1993) 95-105.

[49] P. Gijsman, M. Kroon, M. van Oorschot, The role of peroxides in the thermooxidative degradation of polypropylene, Polym. Degrad. Stab. 51 (1996) 3-13.

[50] J.H. Adams, Analysis of the nonvolatile oxidation products of polypropylene I. Thermal oxidation, J. Polym. Sci. Part A: Polym. Chem. 8 (1970) 1077-1090.

[51] J.H. Adams, Analysis of nonvolatile oxidation products of polypropylene. III. Photodegradation, J. Polym. Sci. Part A: Polym. Chem. 8 (1970) 1279-1288.

[52] J. Lacoste, D. Vaillant, D.J. Carlsson, Gamma-, photo-, and thermally-initiated oxidation of isotactic polypropylene, J. Polym. Sci. Part A: Polym. Chem. 31 (1993) 715-722.

[53] D.M. Mowery, R.A. Assink, D.K. Derzon, S.B. Klamo, R.L. Clough, R. Bernstein, Solid-state 13 C NMR investigation of the oxidative degradation of selectively labeled polypropylene by thermal aging and $\hat{\mathrm{I}}^{3}$-irradiation, Macromolecules 38 (2005) 5035-5046.

[54] J.T. Martin, R.G.W. Norrish, The photochemical decomposition of tert-butyl hydroperoxyde, Proc. R. Soc. A 220 (1953) 322-339.

[55] L. Audouin, S. Girois, L. Achimsky, J. Verdu, Effect of temperature on the photooxidation of polypropylene films, Polym. Degrad. Stab. 60 (1998) 137-143.

[56] G. Geuskens, F. Debie, M.S. Kabamba, G. Nedelkos, New aspects of the photooxidation of polyolefins, Polym. Photochem. 5 (1984) 313-331.

[57] C.H. Bamford, C.F.H. Tipper, Degradation of Polymers, in: Comprehensive Chemical Kinetics, Elsevier, Amsterdam, Oxford; New York, 1975.

[58] G.H. Hartley, J.E. Guillet, Photochemistry of ketone polymers. I. Studies of ethylene-carbon monoxide copolymers, Macromolecules 1 (1968) 165-170.

[59] S.K.L. Li, J.E. Guillet, Photochemistry of ketone polymers. 17. Photodegradation of an amorphous ethylene-propylene copolymer, Macromolecules 17 (1984) 41-50.

[60] J.E. Guillet, Studies of the mechanism of polyolefin photodegradation, Pure Appl. Chem. 52 (1980) 295.

[61] G.H. Hartley, J.E. Guillet, Photochemistry of ketone polymers. II. Studies of model compounds, Macromolecules 1 (1968) 413-417.

[62] J.E. Guillet, Fundamental Processes in the Photodegradation of Polyolefins, in: Stabilization and Degradation of Polymers, Advances in Chemistry Series, 169, American Chemical Society, Washington, 1978, pp. 1-10.
[63] G. Geuskens, M.S. Kabamba, Photo-oxidation of polymers - part V: a new chain scission mechanism in polyolefins, Polym. Degrad. Stab. 4 (1982) 69-76.

[64] G. Geuskens, M.S. Kabamba, Photo-oxidation of polymers: part IX - additional comments about a new chain scission mechanism in polyolefins, Polym. Degrad. Stab. 5 (1983) 399-401.

[65] L.J. Philippart, C. Sinturel, R. Arnaud, Gardette, influence of the exposure parameters on the mechanism of photooxidation of polypropylene, Polym. Degrad. Stab. 64 (1999) 213-225.

[66] C. Sinturel, J.-L. Philippart, J. Lemaire, J.-L. Gardette, Photooxidation of fire retarded polypropylene. I. Photoageing in accelerated conditions, Eur. Polym. J. 35 (1999) 1773-1781.

[67] P. Vink, Photooxidation of polypropylene, J. Appl. Polym. Sci. 35 (1979) 265-273.

[68] P. Vink, The Photo-oxidation of polyolefins - structural and morphological aspects, in: N.S. Allen (Ed.), Degradation and Stabilisation of Polyolefins, Applied Science Publishers, London, 1983, pp. 213-246.

[69] P. Vink, T.J. Van Veen, The mechanism of u.v. stabilization of polypropylene films by 2-hydroxy-4-octyloxybenzophenone, Eur. Polym. J. 14 (1978) 533-537.

[70] P. Gijsman, A. Dozeman, Comparison of the UV-degradation chemistry of unstabilized and HALS-stabilized polyethylene and polypropylene, Polym. Degrad. Stab. 53 (1996) 45-50.

[71] L. Balabán, J. Majer, K. Vesely, Photooxidative degradation of polypropylene, J. Polym. Sci. 22 (1969) 1059-1071.

[72] L.J. Philippart, C. Sinturel, Gardette, influence of light intensity on the photooxidation of polypropylene, Polym. Degrad. Stab. 58 (1997) 261-268.

[73] P. Gijsman, J. Hennekens, J. Vincent, The influence of temperature and catalyst residues on the degradation of unstabilized polypropylene, Polym. Degrad. Stab. 39 (1993) 271-277.

[74] P. Gijsman, The Long-Term Stability of Polyolefins. Wibro Dissertatiedrukkerij, Helmond., in: Technische Universiteit Eindhoven, 1994, pp. 176

[75] C.R. Boss, J.C.W. Chien, Oxygen diffusion limitation in autoxidation of polypropylene, J. Polym. Sci. 4 (1966) 1543-1551.

[76] N.Y. Rapoport, S.I. Berulava, A.L. Kovarskii, I.N. Musayelyan, Y.A. Yershov, V.B. Miller, The kinetics of thermo-oxidative degradation of oriented polypropylene in relation to the structure and molecular mobility of the polymer, Polym. Sci. U.S.S.R. 17 (1975) 2901-2909.

[77] N.Y. Rapoport, A.S. Goniashvili, M.S. Akutin, V.B. Miller, Vysokomol. Soed., 21A, 1979, 2071.

[78] N.Y. Rapoport, N.M. Livanova, V.B. Miller, On the influence of internal stress on the kinetics of oxidation of oriented polypropylene, Polym. Sci. U.S.S.R. 18 (1976) 2336-2341.

[79] M. Iring, S. László-Hedvig, K. Barabás, T. Kelen, F. Tüdos, Study of the thermal oxidation of polyolefins - IX: some differences in the oxidation of polyethylene and polypropylene, Eur. Polym. J. 14 (1978) 439-442.

[80] M. Iring, S. Laszlo-Hedvig, T. Kelen, F. Tudos, L. Fuzes, G. Gamey, G. Bodor, Study of thermal oxidation of polyolefins-VI: change of molecular weight distribution in the thermal oxidation of polyethylene and polypropylene, J. Polym. Sci. Polym. Symp. 57(1 (1976) 55-63.

[81] M. Iring, S. László-Hedvig, F. Tüdos, T. Kelen, Study of the thermal oxidation of polyolefins - XII: thermal oxidation of isotactic and atactic polypropylene in the condensed phase and in solution, Polym. Degrad. Stab. 5 (1983) 467-480.

[82] F. Tüdos, M. Iring, T. Kelen, Oxidation of Polyolefins, in: E.A.V. Patsis (Ed.), International Conference on Advances in the Stabilization and Controlled Degradation of Polymers, 1985.

[83] H.C. Ng, J.E. Guillet, Photochemistry of ketone polymers. 13. Quenching of excited ketone carbonyls by hydroperoxides and peroxides, Macromolecules 11 (1978) 937-942.

[84] S. Commereuc, D. Vaillant, J.L. Philippart, J. Lacoste, J. Lemaire, D.J. Carlsson, Photo and thermal decomposition of iPP hydroperoxides, Polym. Degrad. Stab. 57 (1997) 175-182. 